\title{
Research Paper \\ Efficacy of lifestyle change training on improving self-efficacy, outcome expectations and reducing locus of external control in students
}
Zohreh Mohammad Alipour ${ }^{1}$, Seyed Abdol Majid Bahrainian ${ }^{2}$, Ali Ashghr Asgharnejad Farid ${ }^{3}$
1. Ph.D Student in Consulting, Science and Research Branch, Islamic Azad University, Tehran, Iran.
2. Professor, Department of Psychology, Tehran Medical Branch, Islamic Azad University, Tehran, Iran.
3. Associated Professor, Department of Psychology, Iran University of Medical Sciences, Tehran, Iran.

Citation: Mohammad Alipour Z, Bahrainian S.A.M, Asgharnejad Farid A.A. Efficacy of lifestyle change training on improving selfefficacy, outcome expectations and reducing locus of external control in students. J of Psychological Science. 2022; 20(107): 2107-2124.

URL: https://psychologicalscience.ir/article-1-1266-fa.html
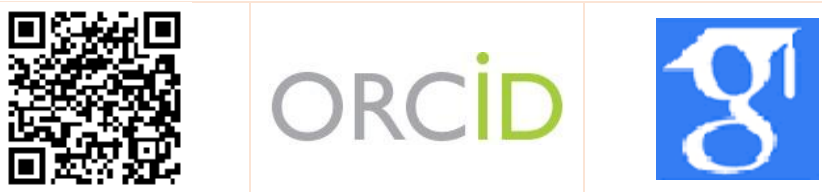

$\underline{10.52547 / J P S .20 .107 .2107}$

\section{A R T I C L E I N F O A B S T R A C T}

Keywords:

Self-efficacy,

Outcome Expectations,

Source of Control,

Lifestyle Change

Training,

Students

Received: 19 May 2021

Accepted: 12 Jul 2021

Available: 21 Jan 2022
Background: Studies have shown that lifestyle change through regulation and orientation to human life is effective on improving individual-educational determinants but a study which addresses the impact of this training on students' self-efficacy, outcome expectations and source of control has been neglected.

Aims: The aim of this study was to determine the effectiveness of lifestyle change training on improving self-efficacy, outcome expectations and reducing locus of external control in students.

Methods: This study was an experimental study with pre-test, post-test with control group. The research population included all students of Islamic Azad University, Tehran Research Sciences Branch in the first semester of the academic year 2020-2021. The study sample included 40 students who were selected by two-stage cluster sampling method and, then, were assigned into experiment and control groups (20 individuals per group) through random assignment method. The research tool were the scales of General Self-Efficacy (Schwarzer and Jerusalem, 1995), Student Outcome Expectations (Landy, 2003) and Source of Control (Rotter, 1966). For the experiment group, lifestyle change training (Van Pay, 2018) was held in eight 90-minute sessions, but the control group did not receive any intervention. Analysis of covariance was used to analyze the data.

Results: The results showed that lifestyle change training was effective in increasing students' selfefficacy, outcome expectations and reducing locus of external control $(\mathrm{p}<0.01)$.

Conclusion: Lifestyle change training can be used by therapists as an efficient way to improve students' self-efficacy and outcome expectations and reduce their external control beliefs, and thus help their academic-career success.

* Corresponding Author: Seyed Abdol Majid Bahrainian, Professor, Department of Psychology, Tehran Medical Branch, Islamic Azad University, Tehran, Iran.

E-mail: majid.bahrainian@gmail.com

Tel: (+98) 9127786737

2476-5740/ (C) 2021 The Authors. This is an open access article under the CC BY-NC-ND license

(https://creativecommons.org/licenses/by-nc/4.0/). 


\section{Extended Abstract}

\section{Introduction}

Given that higher education focuses on outcomebased education, it seems necessary to try to use students' knowledge, awareness and skills. Therefore, understanding the development of knowledge and skills, motivation and attitudes of students in the learning process is important (Diaz, 2019). One of the motivational processes that can be transformed is self-efficacy, which is the beliefs of individuals about their ability to learn and perform at a certain level (Schunk \& DiBenedetto, 2020). These beliefs are a key element of social cognitive theory that play an important role in students' motivation and beliefs about their ability to do homework (Feldman \& Kubota, 2015). Another component of the social cognitive model is outcome expectations, which is defined as a person's assessment and judgment of the extent to which a particular behavior will lead to certain outcomes (Williams, 2010). Therefore, the more positive expectations or hopes a person has for achieving the desired results, the more he will feel satisfied and satisfied with his life, which of course is affected by the physical and mental health resulting from their lifestyle (O'Sullivan, 2011). The source of control is another fundamental issue in the fields of education and psychology, which includes the belief in one's own ability to control what happens in life (Arakeri \& Sunagar, 2017). In educational studies, the relationship between achievement motivation and the source of control has been reported (Sawai, 2018) and in the educational process, the source of control is considered a key factor in motivational orientation (Khadavi \& Vakili, 2011). The source of control or understanding the extent of human control over their actions is influenced by people's lifestyle, because physical ability and mental health, as the main sources of internal attributions of success in the shadow of a healthy lifestyle (Hamidi and Jalilian, 2019).

Lifestyle is the most important regulator of human life and characterizes her movement in life and the world, which can affect academic success or failure through changes in self-efficacy, outcome expectations and source of control (Van Pay, 2018).
In addition, without having a sufficient level of selfefficacy and outcome expectations, individuals will not risk engaging in new behaviors or trying to change their current lifestyle behaviors. Also, if a person believes that he can not affect his mental health and considers it out of his control, he will not want to make a change in his lifestyle. Based on this, it seems that there are interrelationships between social cognitive variables and lifestyle changes (Van Pay, 2018). In this regard, the results of various studies have shown the effect of lifestyle change training on improving various cognitive social skills, such as academic self-concept, self-efficacy, outcome expectations and source of control (Shiri, Ardakani \& Mirsaleh, 2018; Keshavarz, Nazari, Zahrakar \& Sarami, 2015, Van Pay, 2018; Espeland et al., 2017; Olson \& McAuley, 2015).

However, limited research has examined the effectiveness of therapeutic-educational interventions on the components of Bandura social cognitive model, especially interventions based on lifestyle changes. In this study, by teaching lifestyle change to students, it was tried to help educational counselors to access an effective intervention method to improve students' social cognitive skills. Therefore, the present study investigated the issue that how does lifestyle change training affect students' self-efficacy, outcome expectations, and source of control?

\section{Method}

This study was an experimental study with pre-test, post-test with control group. The statistical population of the study included all students of Islamic Azad University, Science and Research Branch of Tehran in the first semester of the academic year 2020-2021, of which 40 people were selected by two-stage cluster sampling method with observing the entry and exit criteria and, then, were assigned into experiment and control groups (20 individuals per group) through random assignment method. Research tests were performed in the pre-test stage and the preliminary results of all 40 students were recorded in the form of a file. In the next stage, the control group waited and the lifestyle change training based on the 8 lifestyle changes considered by Van Pay (2018), ie spending time in nature, communication (social interactions), exercise 
(physical activity), diet and nutrition, sleep, stress management and relaxation, altruistic services and spiritual or religious participation was performed for the experimental group twice a week in 890 -minute sessions. At the end of the treatment intervention, subjects in both experimental and control groups were re-evaluated by the scales of General Self-Efficacy (Schwarzer and Jerusalem, 1995), Student Outcome Expectations (Landry, 2003) and Source of Control (Rotter, 1966). Data were analyzed by descriptive statistics and analysis of covariance.

\section{Results}

Table 1 shows the mean and standard deviation of self-efficacy, outcome expectations and source of control of experimental and control groups in two stages of pre-test and post-test measurement. According to the results of this table, after lifestyle change training, the mean self-efficacy and outcome expectations of the students in the experimental group increased, while their mean external source of control decreased. However, these changes are not seen in the control group.

Table 1. Descriptive statistics of self-efficacy, outcome expectations and source of control in experimental and control groups

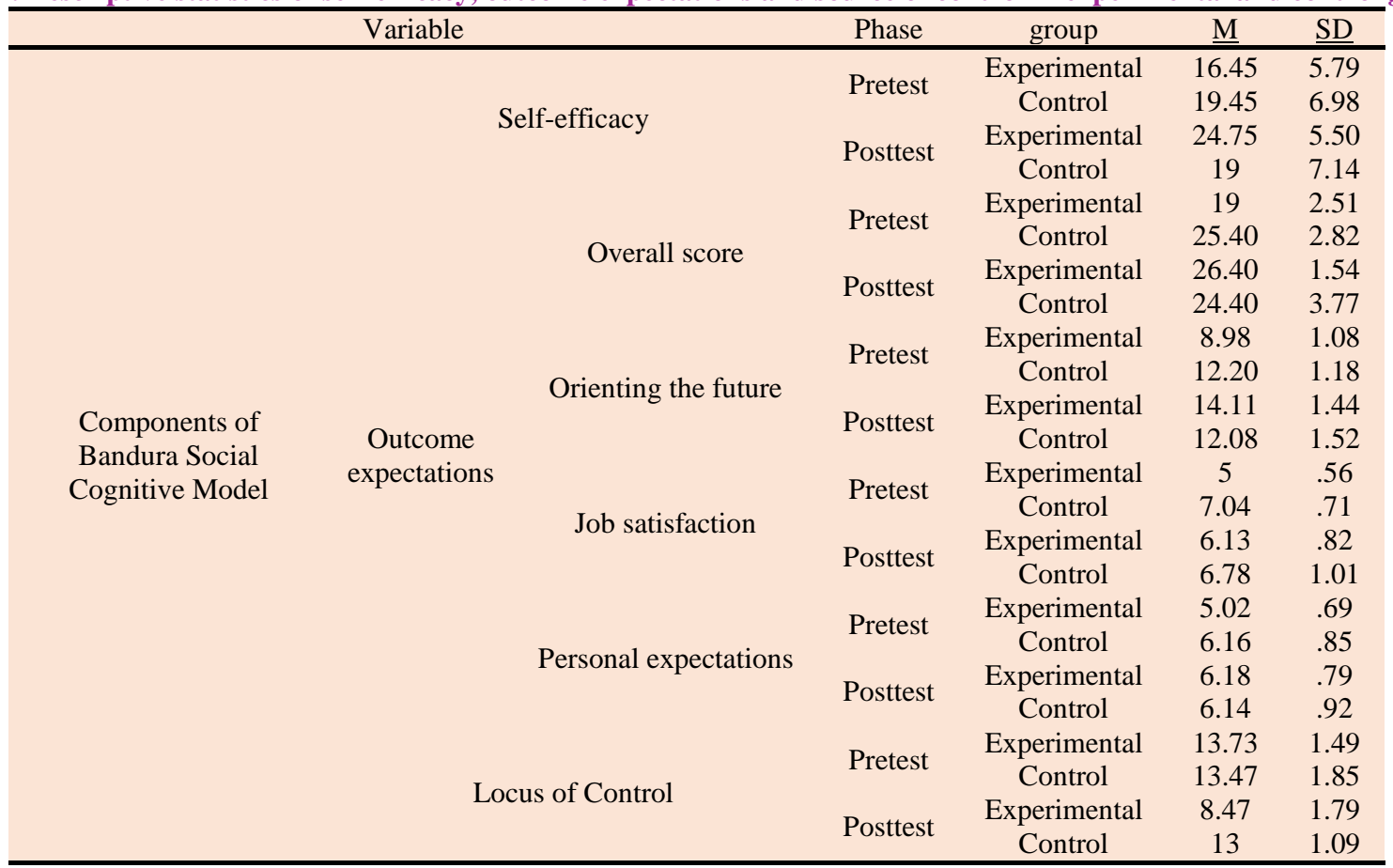

Before applying analysis of covariance, its assumptions were examined. For this purpose, Kalmogorov-Smirnov test was performed to check the normality of research variables and the results showed that the distribution of self-efficacy, outcome expectations and control source scores of experimental and control subjects in the pre-test and post-test stages is normal $(\mathrm{p}<0.05)$. Another assumption was related to the homogeneity of the regression slope, which was determined by examining the interaction between the pretest and the independent variable. This interaction was also not significant $(\mathrm{p}<0.05)$. Also, Box test was performed to investigate the homogeneity of covariance matrices of variance, that the results were not significant $(p<0.05)$ and showed that the covariance matrices of the dependent variable are equal for different levels of the independent variable. Also, Levin test was performed to examine the homogeneity of variances, that the results were not significant $(p<0.05)$ and showed that homogeneity of variances was also established. Finally, the significance of Bartlett's Test of Sphericity $(p<0.05)$ indicated that there was no multicollinearity between the variables of covariate (pre-tests). Therefore, the data did not question the assumptions of using covariance analysis. Therefore, according to the assumptions, the analysis of covariance can be used. The results are reported in 


\section{Monthly Journal of Psychological Science}

Vol. 20, No. 107, Winter(February) 2022
Table 2. As can be seen in Table 2, after removing the effect of pretest by multivariate analysis of covariance, the results showed that there should be a significant difference between the experimental and control groups in at least one of the components of Bandura's social cognitive model and the components of outcome expectations as a result of providing lifestyle change training $(p<0.01)$. Therefore, in order to investigate the significance observed in which of the research variables, in Table 2, ANCOVA was used.

Table 2. MANCOVA on the mean post-test of research variables of experimental and control groups with pre-test control

\begin{tabular}{|c|c|c|c|c|c|c|c|c|}
\hline Variables & Test & Value & $\mathrm{F}$ & Hypothesis df & Error df & Sig. & $\begin{array}{l}\text { Partial Eta } \\
\text { Squared }\end{array}$ & $\begin{array}{c}\text { Observed } \\
\text { Power }^{\mathrm{d}} \\
\end{array}$ \\
\hline \multirow{4}{*}{$\begin{array}{c}\text { Components of } \\
\text { Bandura Social } \\
\text { Cognitive } \\
\text { Model }\end{array}$} & Pillai's Trace & .84 & 28.10 & 3 & 33 & .000 & .84 & 1 \\
\hline & Wilks' Lambda & .16 & 28.10 & 3 & 33 & .000 & .84 & 1 \\
\hline & Hotelling's Trace & 5.35 & 28.10 & 3 & 33 & .000 & .84 & 1 \\
\hline & $\begin{array}{c}\text { Roy's Largest } \\
\text { Root }\end{array}$ & 5.3 & 28.10 & 3 & 33 & .000 & .84 & 1 \\
\hline \multirow{4}{*}{$\begin{array}{c}\text { Components of } \\
\text { Outcome } \\
\text { expectations }\end{array}$} & Pillai's Trace & .68 & 11.43 & 3 & 33 & .000 & .69 & 1 \\
\hline & Wilks' Lambda & .32 & 11.43 & 3 & 33 & .000 & 69 & 1 \\
\hline & Hotelling's Trace & 2.18 & 11.43 & 3 & 33 & .000 & .69 & 1 \\
\hline & $\begin{array}{c}\text { Roy's Largest } \\
\text { Root }\end{array}$ & 2.18 & 11.43 & 3 & 33 & .000 & .69 & 1 \\
\hline
\end{tabular}

Table 3. ANCOVA on mean post-test of self-efficacy, outcome expectations and source control of groups with pre-test control

\begin{tabular}{|c|c|c|c|c|c|c|c|c|c|}
\hline \multicolumn{4}{|c|}{ Variable } & SS & $\mathrm{df}$ & MS & $\mathrm{F}$ & $\eta 2$ & power \\
\hline \multirow{12}{*}{$\begin{array}{c}\text { Components of } \\
\text { Bandura Social } \\
\text { Cognitive Model }\end{array}$} & \multirow{2}{*}{\multicolumn{2}{|c|}{ Self-efficacy }} & Pretest & 195.72 & 1 & 195.72 & $98.98^{* *}$ & .81 & 1 \\
\hline & & & Group & 3688.70 & 1 & 3688.70 & $129.48^{* *}$ & .73 & 1 \\
\hline & & \multirow{2}{*}{ Overall score } & Pretest & 9120.48 & 1 & 9120.48 & $66.23^{* *}$ & .70 & 1 \\
\hline & & & Group & 17474.58 & 1 & 17474.58 & $73.24^{* *}$ & .73 & 1 \\
\hline & & \multirow{2}{*}{$\begin{array}{l}\text { Orienting the } \\
\text { future }\end{array}$} & Pretest & 2005.53 & 1 & 2005.53 & $47.70^{* *}$ & .64 & 1 \\
\hline & Outcome & & Group & 3022.68 & 1 & 3022.68 & $78.54^{* *}$ & .74 & 1 \\
\hline & expectations & \multirow{2}{*}{ Job satisfaction } & Pretest & 412.65 & 1 & 412.65 & $23.77^{* *}$ & .48 & 1 \\
\hline & & & Group & 1085.45 & 1 & 1085.45 & $46.42^{* *}$ & .63 & 1 \\
\hline & & \multirow{2}{*}{$\begin{array}{c}\text { Personal } \\
\text { expectations }\end{array}$} & Pretest & 349.75 & 1 & 349.75 & $25.08^{* *}$ & .47 & 1 \\
\hline & & & Group & 698.08 & 1 & 698.08 & $59.14^{* *}$ & .69 & 1 \\
\hline & \multirow{2}{*}{\multicolumn{2}{|c|}{ Locus of Control }} & Pretest & 714.08 & 1 & 714.08 & $79.92^{* *}$ & .76 & 1 \\
\hline & & & Group & 856.14 & 1 & 856.14 & $95.96^{* *}$ & .79 & 1 \\
\hline
\end{tabular}

$\mathrm{p}<0 / 05^{*}, \mathrm{p}<0 / 01$

As shown in Table 3, in self-efficacy $(\mathrm{F}=129.48$, $\mathrm{p}<0.01)$, outcome expectations $(\mathrm{F}=73.34, \mathrm{p}<0.01)$ and control source $(\mathrm{F}=95.96, \mathrm{p}<0.01)$, difference between the groups were significant. Regarding the components of outcome expectations, the difference between the groups was significant $(\mathrm{p}<0.01)$.

\section{Conclusion}

The aim of this study was to determine the effectiveness of lifestyle change training on improving self-efficacy, outcome expectations and reducing locus of external control in students. The findings of this study indicated the effectiveness of lifestyle change training on improving self-efficacy, outcome expectations and reducing locus of external control in students. This finding is generally consistent with the results of research by Shiri et al.
(2018), Keshavarz et al. (2015), Van Pay (2018), Espeland et al. (2017) and Olson \& McAuley (2015) which have shown the effectiveness of this method in improving variety of social cognitive skills, such as academic self-concept, self-efficacy, outcome expectations and source of control.

Explaining the effectiveness of this treatment, it can be said that in lifestyle change training, various techniques are used to improve coping skills, correct decision and problem solving, exercise, recreation and healthy eating, interpersonal communication and self-awareness that are the main components of selfefficacy (Cannity et al., 2021). In addition, this health-oriented lifestyle intervention promoted hope and positive outcome expectations by involving individuals in self-care behaviors, gaining social support, and improving psychological symptoms 
(Benson, 2016); Because this intervention enabled the individual to act positively and harmoniously in relation to other human beings, society, culture and environment, and to expect appropriate results from his actions. Finally, lifestyle change trainings maintained responsibility for physical, emotional, social and psychological health, which play an important role in changing a person's source of control from an external source of control to an internal source of control (Van Pay, 2018). Due to time constraints and the prevalence of coronavirus (Covid-19), it was not possible to conduct a follow-up test and measure the stability of the intervention at different time intervals. Finally, it is suggested that the Therapeutic Lifestyle Changes (TLCs) be used in higher education centers in different cities and compare its effectiveness with other therapies.

\section{Ethical Considerations}

Compliance with ethical guidelines: This article is extracted from the Ph.D. dissertation of the first author, which was approved in the Consulting Department, Tehran Science and Research Branch, Islamic Azad University with the proposal approval date of 01.01.2020. Ethical considerations like gaining the informed consent of the participants and the confidentiality were observed in this research.

Funding: This study was conducted as a Ph.D. thesis with no financial support.

Authors' contribution: The first author was the senior author, the second one was the supervisor and the third one was the advisor.

Conflict of interest: There is no conflict of interest in this study. Acknowledgments: All students participating in the research, respected professors and officials of Islamic Azad University, Tehran Science and Research Branch who helped and accompanied the authors in conducting this research, are thanked and appreciated. 


\section{اثربخشى آموزش تغيير سبكى زندكى بر بهبود خود كار آمدى، انتظارات ييامد و كاهش منبع كنترل بيرونى دانشجويان

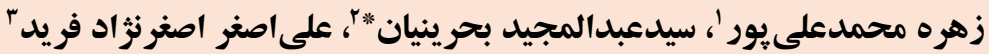

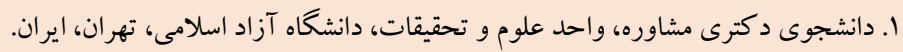

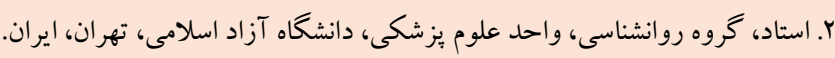 \\ r. دانشيار، گروه روانشناسى، دانشكاه علوم بز شكى ايران، تهران، ايران.}

\begin{tabular}{|c|c|}
\hline جكيده & 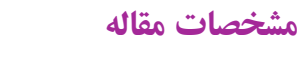 \\
\hline زمينه: مطالعات نشان دادهاند كه تغيير سبك زندگى از طريق تنظيم و جهتدهى به زندگى انسان بر ارتقاء تعيين كندههاى فردى - آموزشى & 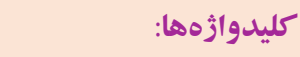 \\
\hline مؤثر است، اما يُووهشى كه به تأثير آموزش آن بر خود كار آمدى، انتظارات يِامد و منبع كنترل دانشجويان يرداخته باشد، مغفول مانده است. & خو د كار آمدى، \\
\hline \multirow{2}{*}{ هيرونى دانشجويان بودو. هُوهش حاضر تعيين اثربخشى آموزش تغيير سبك زندگى بر بهبود خود كار آمدى، انتظارات بيامد و كاهش منبع كنترل } & 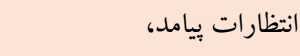 \\
\hline & منبع كنترل، \\
\hline روش: تحقيق حاضر مطالعهاى آزمايشى با طرح بيش آزمون، بِ آزمون با گروه گو اه بود. جامعه يُوهش متشكل از دانشجويان دانشكاه & 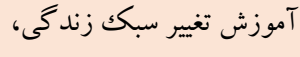 \\
\hline 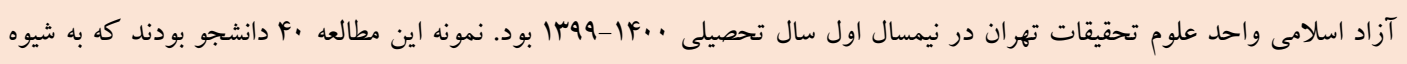 & دانشجويان \\
\hline \multicolumn{2}{|l|}{ نمونه گيرى خوشهاى دومر حلهاى انتخاب و با گمارش تصادفى در گروههاى آزمايش و گو اه (هر گروه .ب نفر) قرار گرفتند. ابزار يُزوهش } \\
\hline \multicolumn{2}{|l|}{ مقياسهاى خود كار آمدى عمومى (شوارزر و جروسلم، 199ه)، انتظارات بيامد دانشجو (لندى، r..r) و منبع كنترل (راتر، 1994) بودند. } \\
\hline \multicolumn{2}{|l|}{ 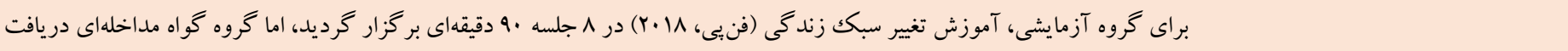 } \\
\hline \multicolumn{2}{|l|}{ نكرد. براى تحليل دادهها از تحليل كواريانس استفاده گرديد. } \\
\hline \multicolumn{2}{|l|}{ يافته ها: آموزش تغيير سبكك زندگى بر افزايش خود كار آمدى، انتظارات بيامد و كاهش منبع كنترل بيرونى دانشجويان اثربخش بود } \\
\hline$(\mathrm{p}<\cdot / \cdot 1)$ & 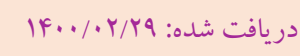 \\
\hline نتيجه كيرى: آموزش تغيير سبك زند گى مى تواند بهعنوان روشى كار آمد در بهبود خود كارآمدى و انتظارات ييامد دانشجويان و كاهش & 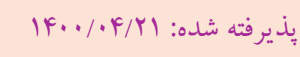 \\
\hline باورهاى كنترل بيرونى آنان توسط درمانخران مورد استفاده قرار گيرد و در نتيجه به موفقيت تحصيلى - شغلىشان كمكك نمايد. & 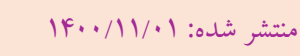 \\
\hline
\end{tabular}

* نويسنده مسئول: سيدعبدالمجيد بحرينيان، استاد، گروه روانشناسى، واحد علوم يزشكى، دانشخاه آزاد اسلامى، تهران، ايران. راياناهه: majid.bahrainian@gmail.com 
افزايش بيدا كرده و آمادكى و استقامت بيشترى نسبت به آنهايى كه از

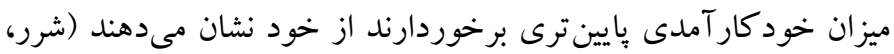
مؤلفه ديخر در مدل شناختى اجتماعى انتظارات بيامد است كه به عنوان

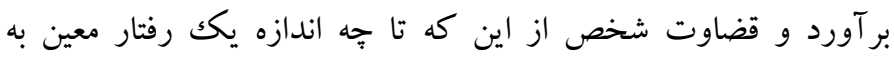

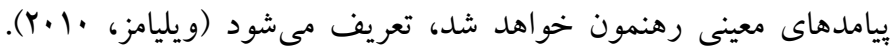

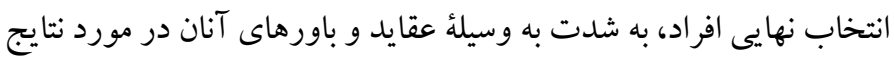

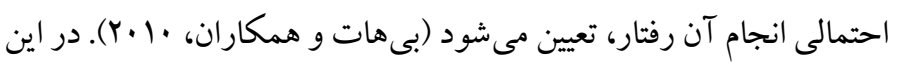

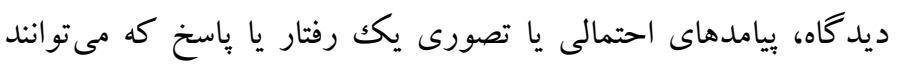

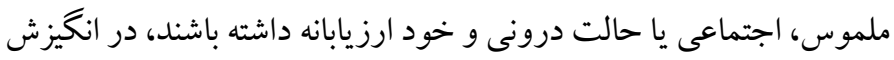
فرد براى اقدام و عمل مهم تلقى مىشوند (بونيتز، لارسن و آرمسترانگك،

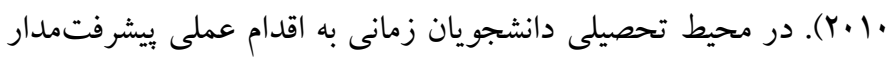

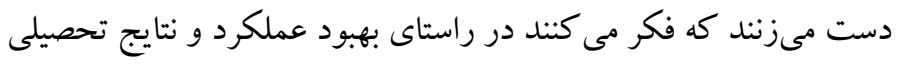
آنان است يا بِ از اتمام تحصيل و در يافتن شغل برايشان مفيد خو اهد بود. از اين رو، هر قدر فرد انتظارات مثبت يا اميد بيشترى براى كسب نتايج مطلوب داشته باشد، احساس رضايت و خشنودى بيشترى از زندگى خرى خود خواهد داشت كه البته اين انتظارات تحت تأثير سلامت جسمى و روانى

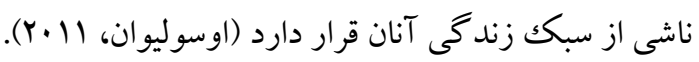
از مباحث اساسى ديخرى كه در حوزههاى تعليم و تربيت و روانشناسى

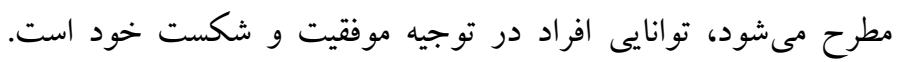

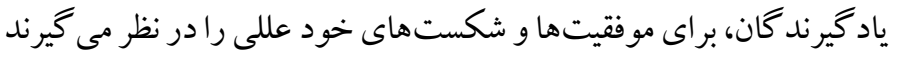

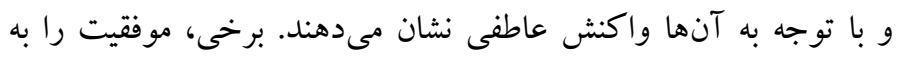
عوامل درونى و شكست را به عوامل بيرونى نسبت مىدهند (حميدى و

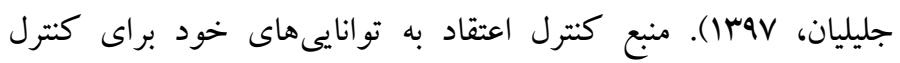

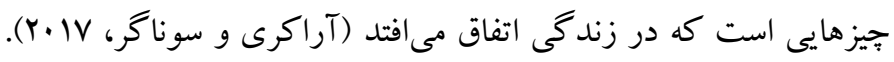
در مطالعات تربيتى و آموزشى ارتباط بين انخيزش ييشرفت با منبع كنترل

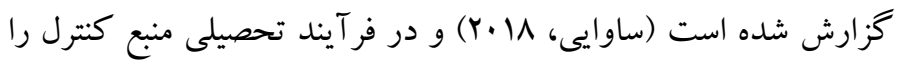

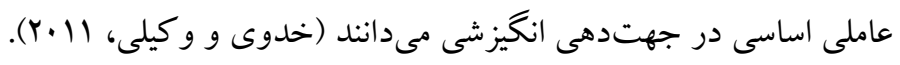
جنانجه فردى احساس كند كه رويدادهاى زندگ تحت كنترل خودش مى باشد و نسبت به آنها احساس مسئوليت مى كند،

3 . locus of control

${ }^{4}$. Mental Health
مقاله

همه ساله كشورها مبالغ قابل توجهى از در آمد ملى خود راصرف آموزش

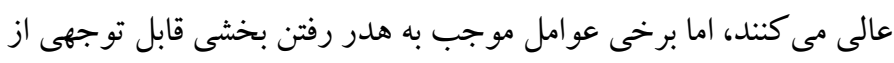

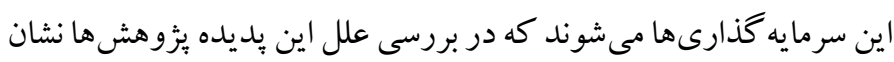

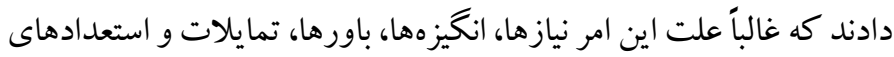

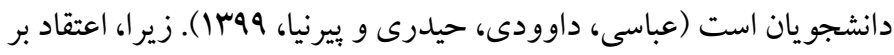
اين است كه فر آيندهاى شناختى و عاطفى است كه انسان را بر مى دانخيز انند، به رفتار او جهت مىدهند و باعث استمرار رفتارها مىشوند؛ لذا تمركز

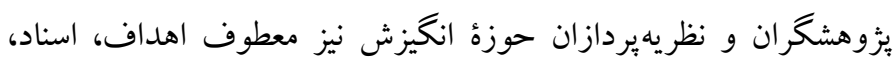
انتظارات، ارزشها و هيجانات شده است (ديكسون، هاوه و هميلتون،

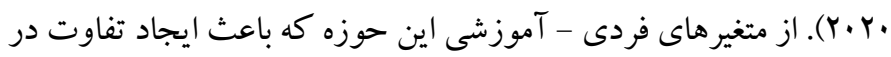

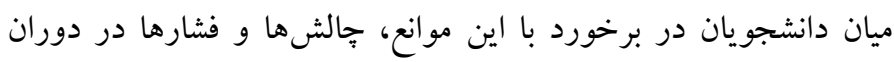

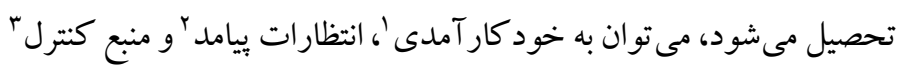

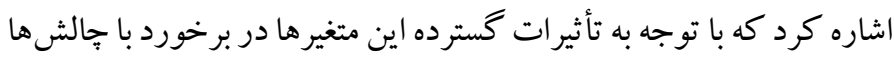

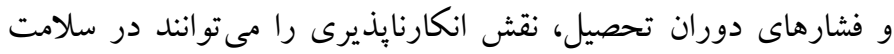

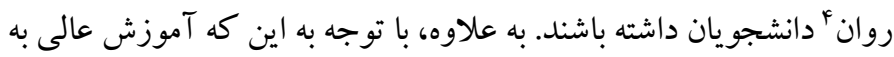

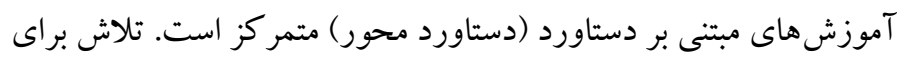

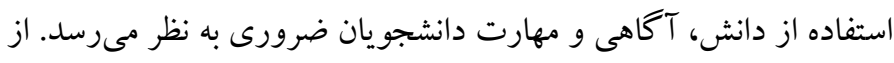

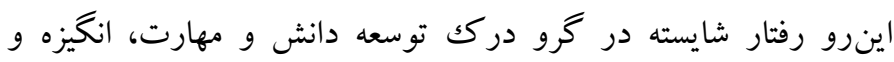
نخرش هاى مربوط است و محققان معتقدند كه در زمينه آموزش، افكار و

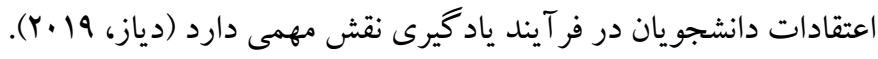

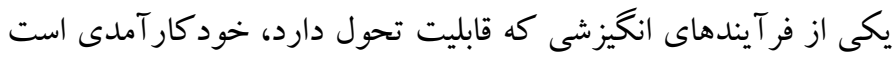

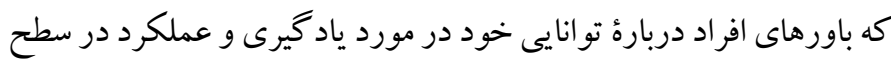

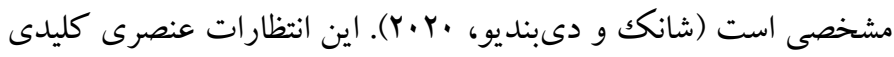
از نظريه شناختى اجتماعى هستند كه نقش مهمى در انظيزش و باورهاى

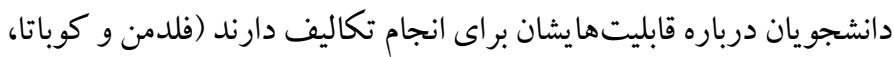

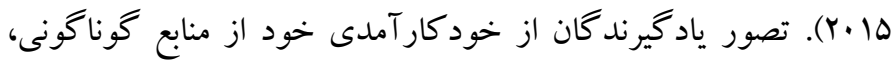

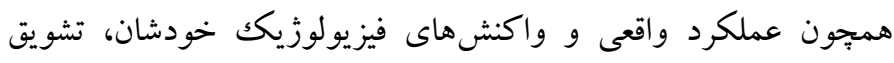

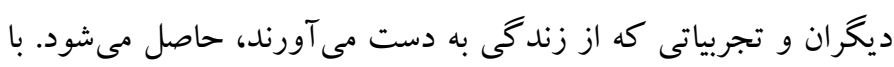
افزايش ميزان خودكارآمدى يادگيرندگان، عملكرد تحصيلى آنان نيز

1. self-efficacy

${ }^{2}$. outcome expectations 
بود. بر اين اساس به نظر مىرسد روابط متقابلى بين متغيرهاى شناختى

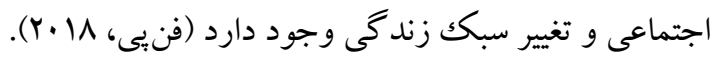

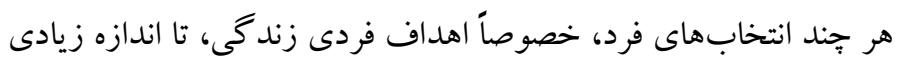

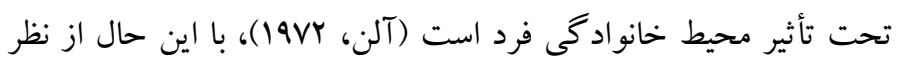

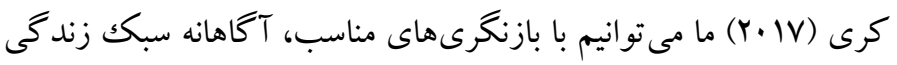

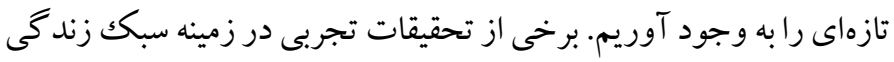

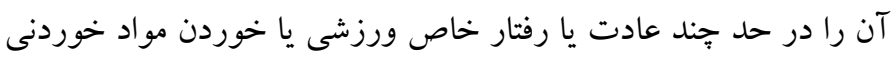

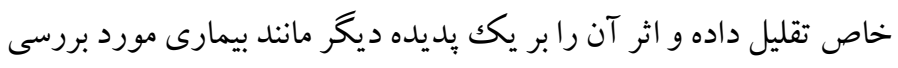

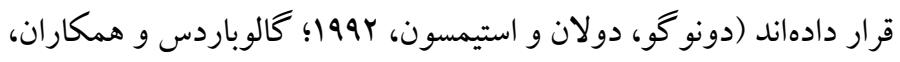

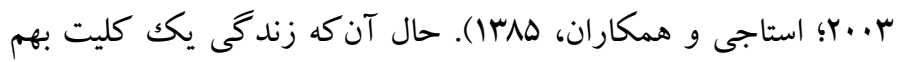
يبيوسته است و لذا سبكك زندگى نيز واجد اين كليت است. در همين راستا، والش (Y.11) روانشناس آمريكايى در مقالهاى خود اظهار مىدارد كه

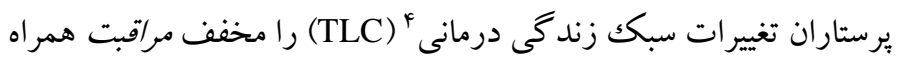

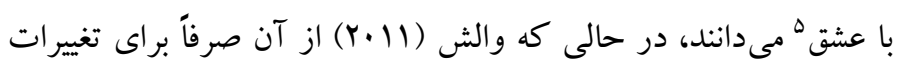

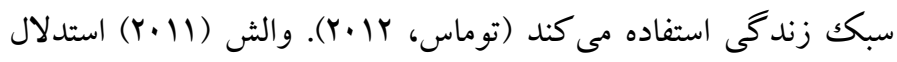
مى كند كه متخصصان بالينى سلامتروان از TLC كمتر استفاده مى كنند، حتى اكر بدانند اثربخشى آنها در درمان برخى اختلالات به به اندازه

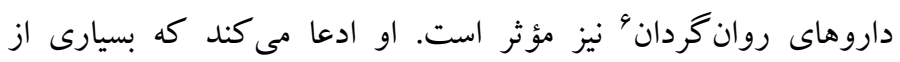

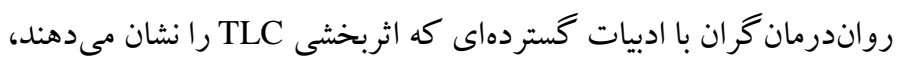

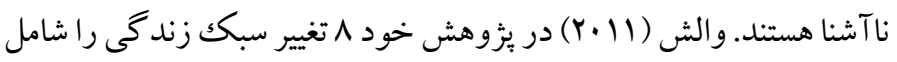
وقت گذراندن در طبيعت، خواب، ورزش ^ُ (فعاليت بدنى)، رزيم غذايى و تغذيه'، فعاليتهاى تفريحى "، مديريت استرس و آرامسازى" ل، خدمات

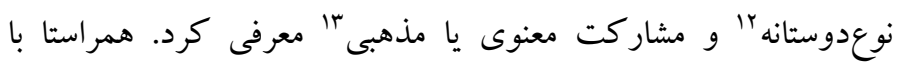
يُزوهش فنيى (Y) (Y)، در اين يُزوهش نيز براى بر برسى اثربخشى تغييرات

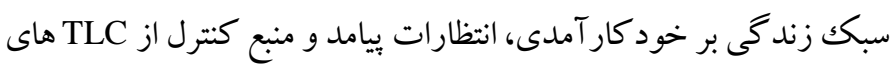

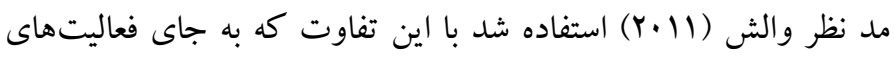

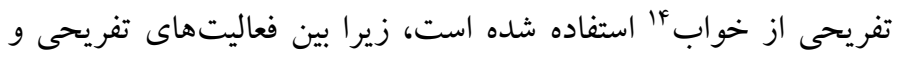

${ }^{8}$. exercise

${ }^{9}$. nutrition/diet

${ }^{10}$. recreational activities

${ }^{11}$. relaxation/stress management

12. altruistic service

13. religious or spiritual involvement

${ }^{14}$. sleep
داراى منبع كنترل درونى است و در صورتى كه احساس كند، رويدادهاى

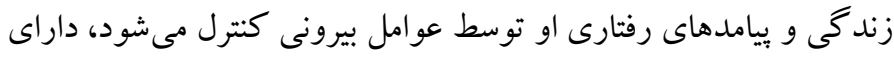

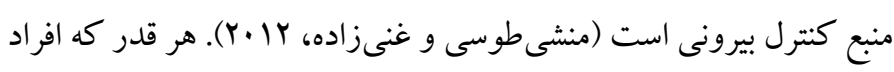

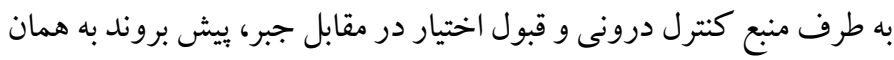

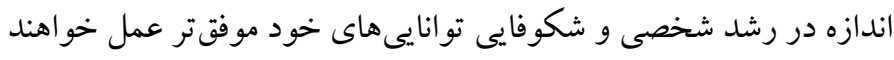
كرد. به راحتى مى توان فهميد كه منبع كنترل يا در كك ميزان كنترل انسانها

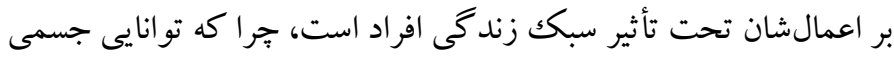
و سلامتروانى، به عنوان منابع اصلى اسنادهاى درونى موفقيت در سايه

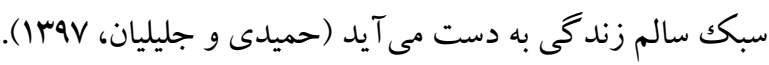
تلاش براى غلبه بر احساس حقارت و رسيدن به برترى در همه انسانها ديلده

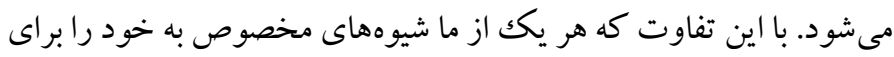

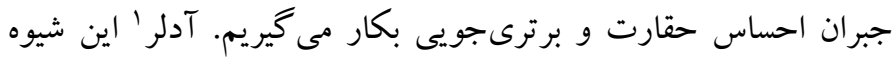

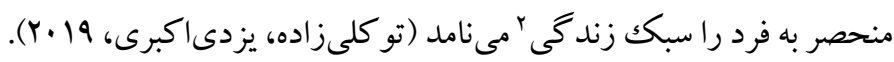

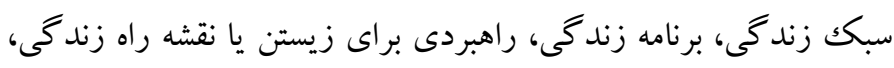

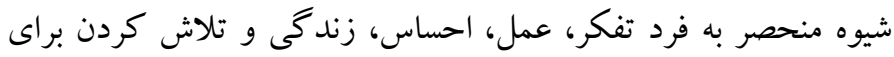

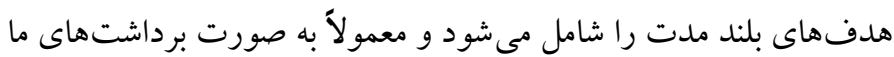

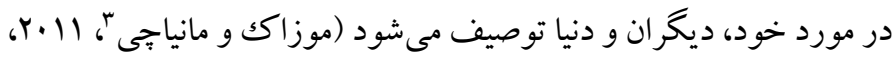

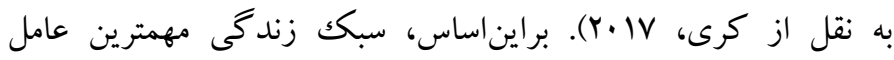

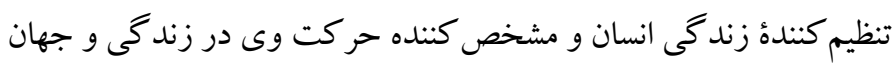
است كه مىتواند موفقيت يا شكست تحصيلى را از طريق تغيير در

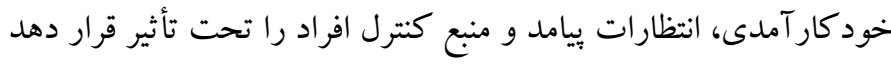

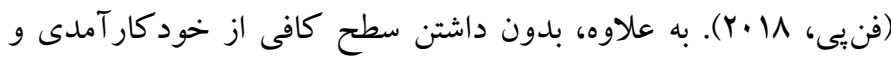

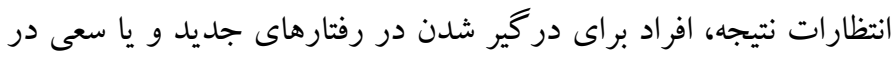

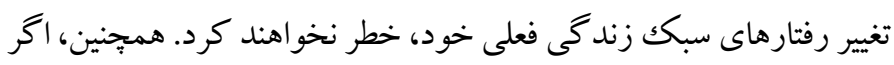

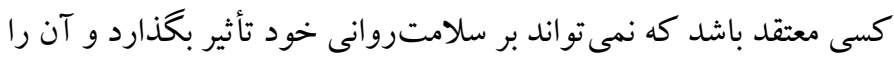

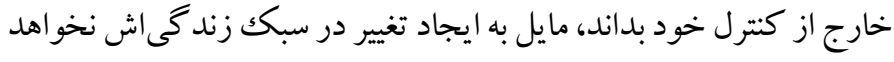

1. Adler

${ }^{2}$. lifestyle

${ }^{3}$. Mosak \& Maniacci

${ }^{4}$. therapeutic lifestyle changes (TLC)

${ }^{5}$. tender loving care

${ }^{6}$. psychotropic medications

7. spending time in nature 


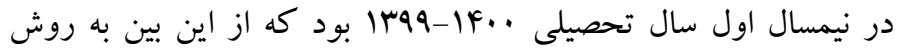
نمونه گيرى خوشهاى به صورت دو مرحلهاى (واحد مرحله اول: رشته

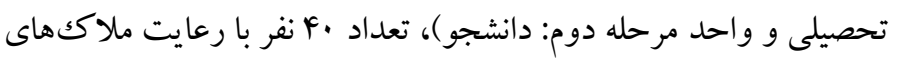

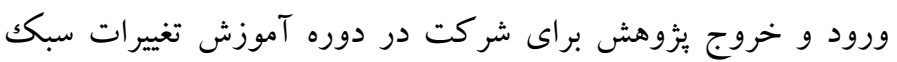

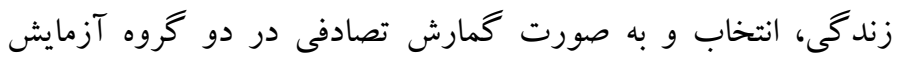

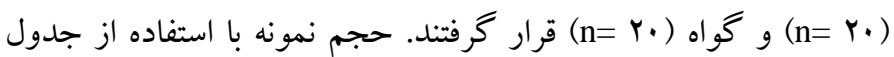
كوهن و تعيين اندازه اثر با توجه به هـ/

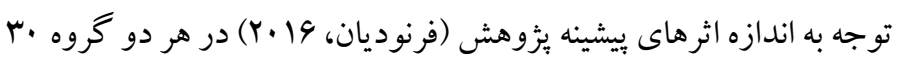

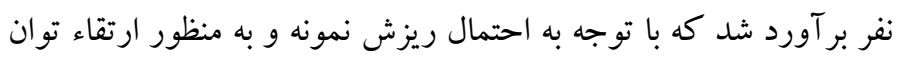

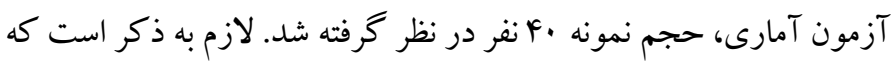
ابتدا • •هr نفر بهعنوان نمونه انتخاب و سجبس از ميان اين دانشجويان، تعداد

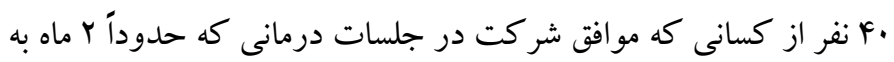

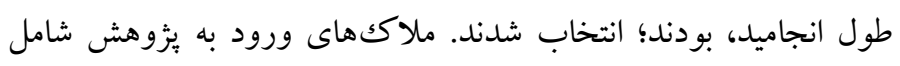

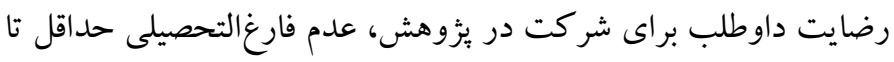

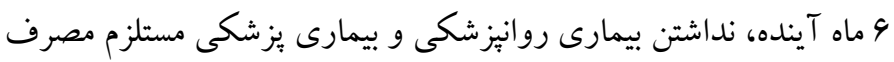

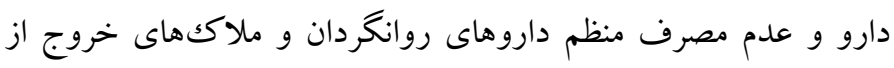
بزّوهش شامل داشتن سابقه بسترى در بخش روانيزشكى، حضور در

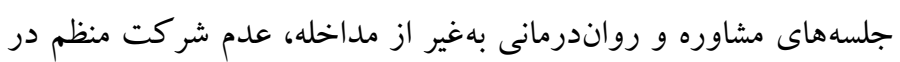
جلسات و عدم همكارى در تكميل برسشنامهها در دو مرحله بيش آزمون و بس آزمون بودند. از دانشجويان انتخاب شده ثبتنام بهعمل آمد و اطلاعات

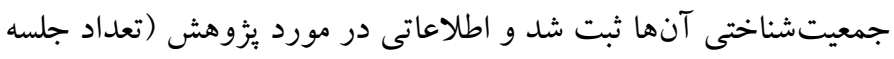

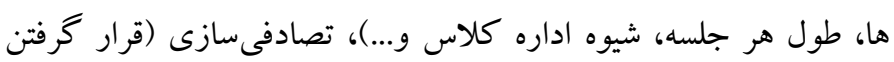

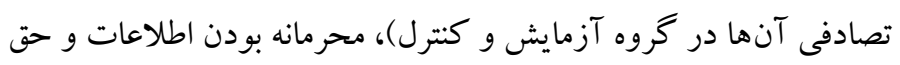
خروج از يزوهش در هر زمانى كه مىخواهند، داده شد و موافقت آنها

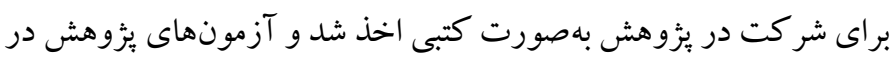

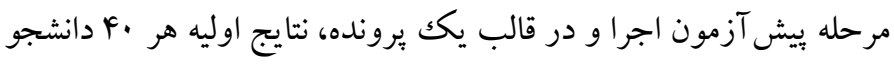

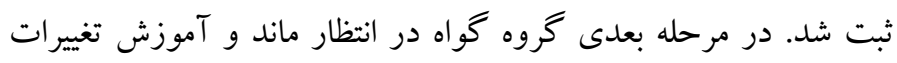

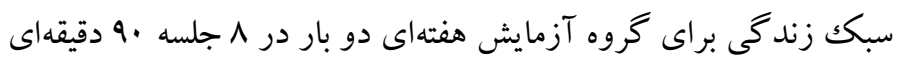

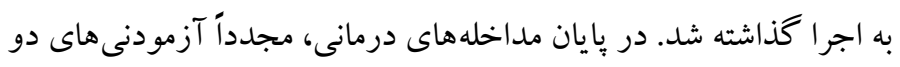

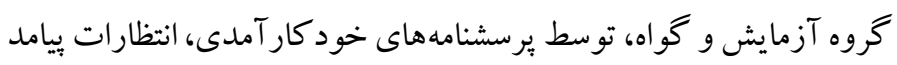

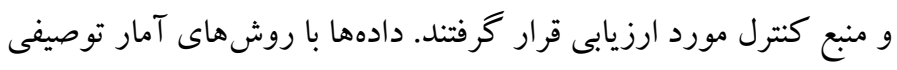
و تحليل كواريانس تحليل گرديدند.
اوقات فراغت، فعاليت بدنى و تعامل اجتماعى رابطه بيجيجيدهاى وجود دارد،

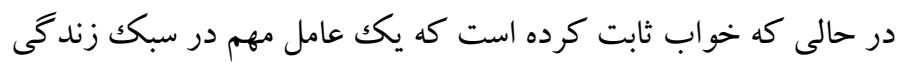

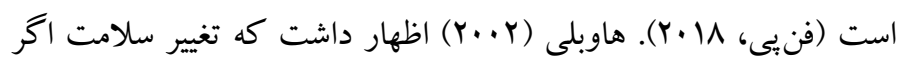
تنها اطمينان دادن و توانمندسازى بدون در نظر گرفتن مؤلفههاى دانش و و

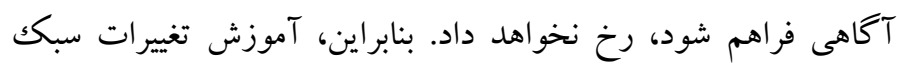

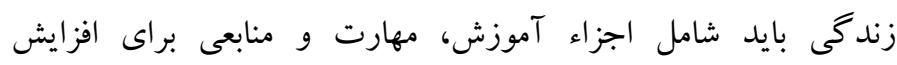

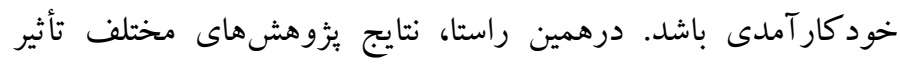

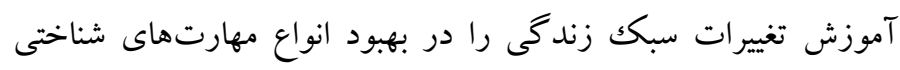
اجتماعى، نظير خودينداره تحصيلى، خود كار آمدى، انتظارات بيامد و منبع

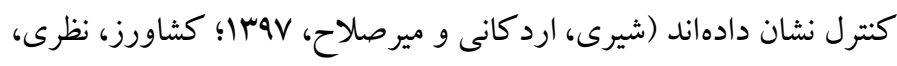

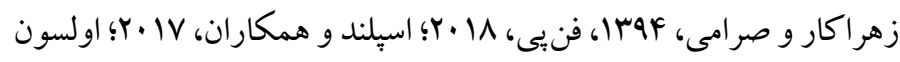

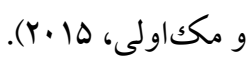
با توجه به اهميت نقش خود كار آمدى، انتظارات بيامد و منبع كنترل به مانه

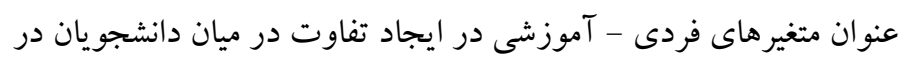

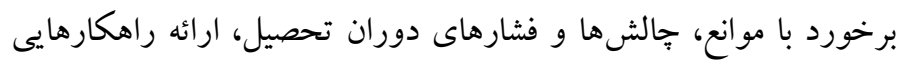
جهت ارتقاء اين عوامل اهميت دارد. اين در حالى است كه با توجه به مبانى دوردي نظرى و يثزوهشى بررسى شده، يزوهشهاى محدودى وجود دارد كه به

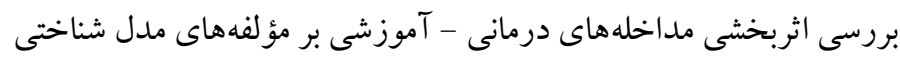

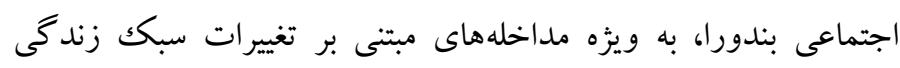

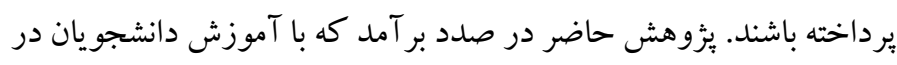

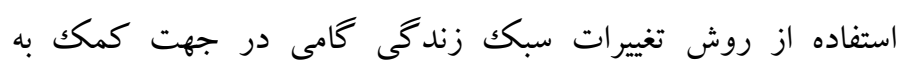

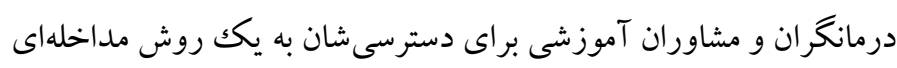

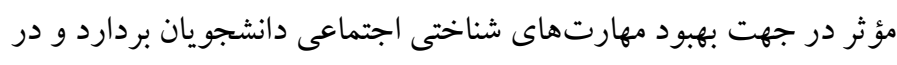
صورت كار آمدى اين روش، نتايج و روش آموزشى در اختيار مراكز

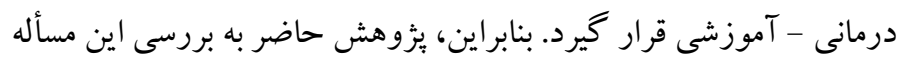

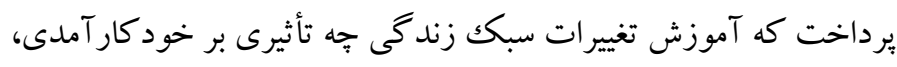
انتظارات ييامد و منبع كنترل دانشجويان دارد؟ لعير

روش

الف) طرح يخووهش و شركت كنند كان: طرح بثوهش آزمايشى از

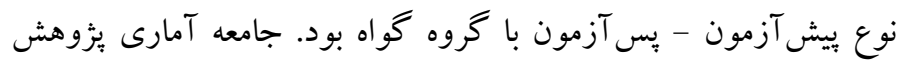

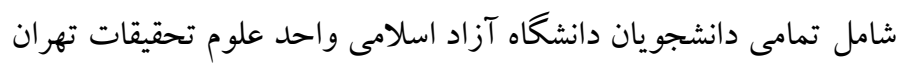


به طور خلاصه در اين جلسات ضمن بيان اهميت سبكك زندكى و آشنايى

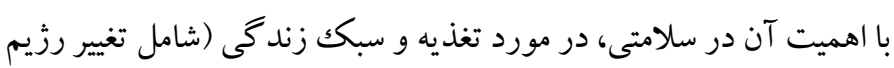

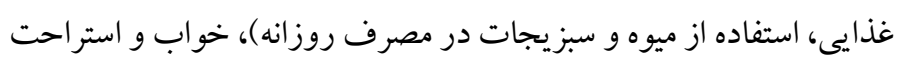
(شامل داشتن برنامه منظم براى خواب و بيدارى، ارائه توصيههاى عملى ونى

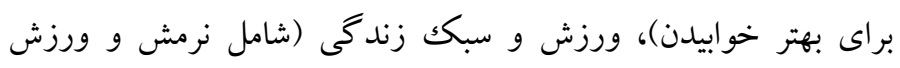

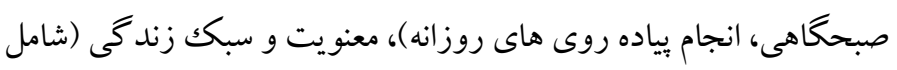
اهميت نقش معنويت در سلامت روحى و روانى)، مديريت استرس و سبك إنى زندكى (فعاليتهايى كه منجر به كاهش استرس مىشود، رزيم غذايى،

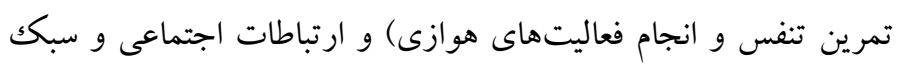

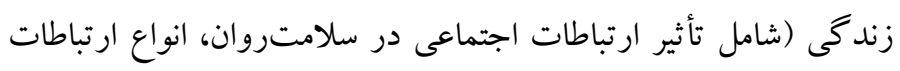

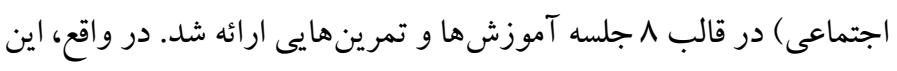

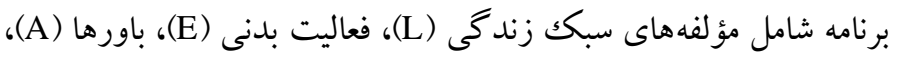

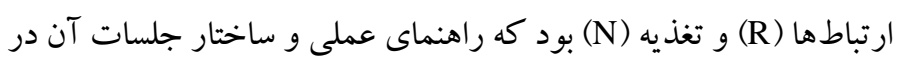
جدول ا خزارش شده است.
يروتكل آموزش تغييرات سبك زندگى توسط محقق تدوين گرديد كه بر

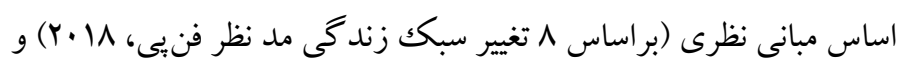

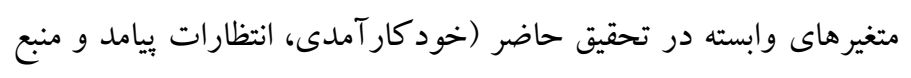

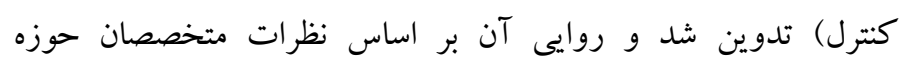

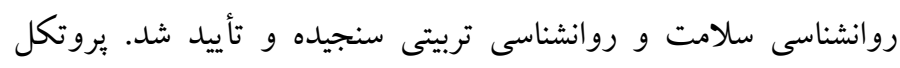

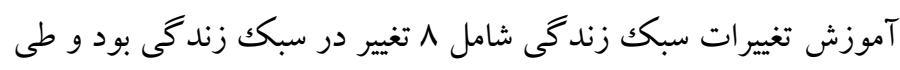

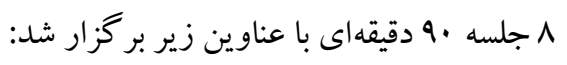

$$
\begin{aligned}
& \text { l. وقت گذراندن در طبيعت } \\
& \text { r. . ارتباط (تعاملات اجتماعى) } \\
& \text { r. ورزش (فعاليت بدنى) } \\
& \text { ع. ـ رزيم غذايى و تغذيه }
\end{aligned}
$$

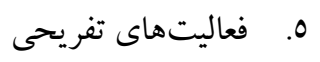

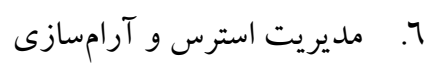

\begin{tabular}{|c|c|c|}
\hline فعاليت & 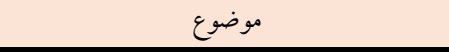 & جلسات \\
\hline معرفى برنامه، ارائه توضيحاتى در زمينه تغيير سبك زندگى، تصويرسازى ذهنى، اهميت خوديايى و ثبت آن، & رويكرد كنترل استرس، و سبك زندگى & اول \\
\hline 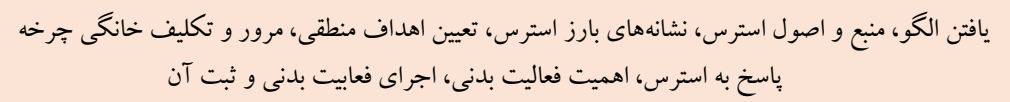 & 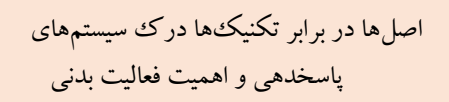 & دوم \\
\hline خود گويىها، به جالش كشيدن افكار مخرب و استرس آور، نقش احساسات و منشأ آن، توضيحاتى در زمينه & 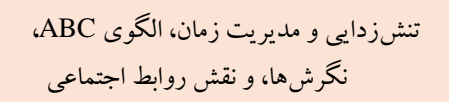 & سوم \\
\hline مرور كاربركَها، توضيحاتى درباره جرأتورزى، اهميت تغذيه مناسب، مديريت استرس، نقش حمايت & جرأتورزى و اهميت تغذيه & جهارم \\
\hline 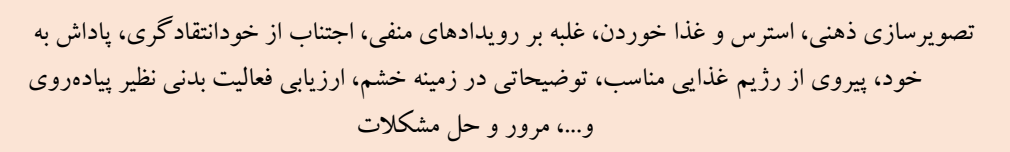 & تنشزدايى و كنترل خشم، تقويت، رزيم غذايى مناسب ورزش & ينجم \\
\hline معرفى آزمون، واقعيت ساختن يكك نردبان دو طرفه، تنشزدايى از طريق فراخوانى، باورهاى مر تبط با ناكامى و & $\begin{array}{l}\text { آزمون واقعيت و نردبان دو طرفه، دامهاى } \\
\text { نكرشى و حل مسأله }\end{array}$ & ششم \\
\hline استرس به عنوان يك زنجيره، شكستن زنجيره، مرور زنجيره رفتارى بيماران، تعيين نقشها و اهداف & زنجيرههاى رفتارى و اهميت نقشها & هنتم \\
\hline رويدادهاى جالشانگيز زندگى، يُشگيرى از عود و كنترل، مرور و جمعبندى برنامه & تقويت خود در برابر محيطى استرسزا & هشتم \\
\hline
\end{tabular}

$$
\begin{aligned}
& \text { V. خدمات نوعدوستانه }
\end{aligned}
$$

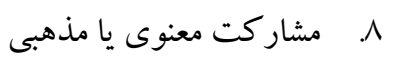

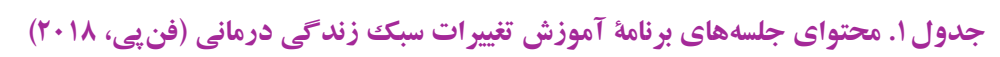

است. نسخه اوليه برسشنامه خود كار آمدى عمومى در سال $19 \vee 9$ توسط

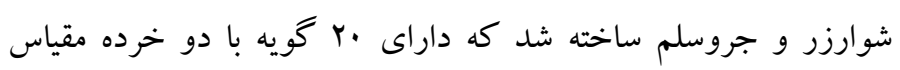
جدا كانه خود كار آمدى عمومى و خود كار آمدى اجتماعى بود كه در در سال

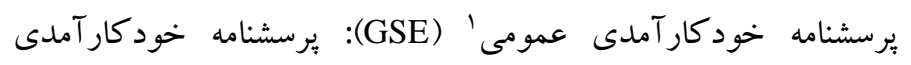
عمومى (GSE) در آلمان توسط شوارزر و جروسلم (1990) طراحى شده

1. General Self-Efficacy Scale (GSE) 
است. روايى مقياس انتظارات بيامد از طريق محاسبه ضريب همبستخى با مقياسهاى مشابه، به عنوان روايى همزمان نشان داده شده است. نتايج

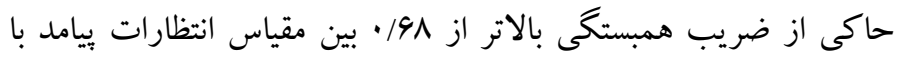

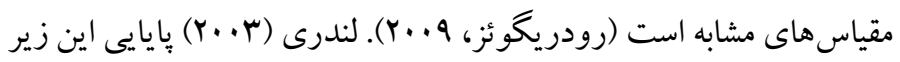

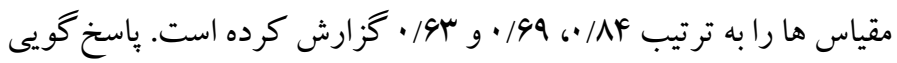
به سؤالات اين برسشنامه بر اساس طيف ليكرت انجام شد كه دامنهاى بين

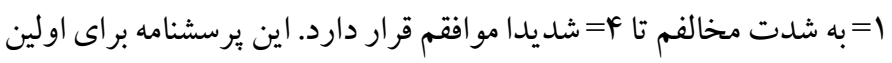

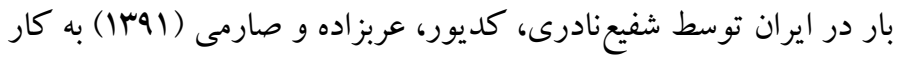

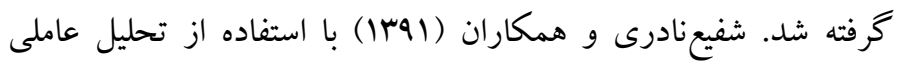
اكتشافى با روش مؤلفهاى اصلى، علاوه بر عامل كلى انتظارات بيامد

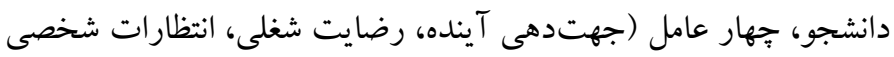

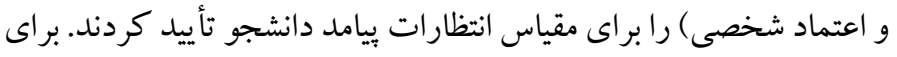

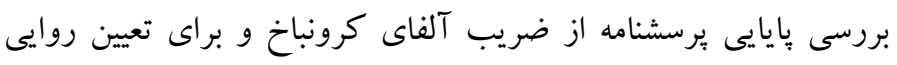
عاملى آن از تحليل عاملى تأييدى استفاده شد. نتايج نشان داد كه برسشنامه برسي

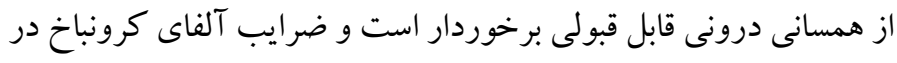
زير مقياسهاى آن بين 90/· تا V9/· • است. همجنين براى تعيين روايى عاملى از تحليل عاملى تأييدى استفاده شد، كه نتايج تحليل عاملى تأييدى مؤيد اين بود كه ساختار برسشنامه برازش قابل قبولى با داده ها دارد و كليه شاخص هاى نيكويى برازش، مدل را تأييد مى كنند. برسشنامه منبع كنترل راتر؟ (RLCS): اين برسشنامه توسط راتر (1999) براى سنجش انتظارات افراد در منبع كنترل با وج سؤال تدوين شده است.

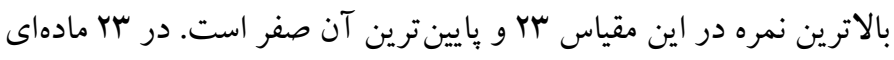

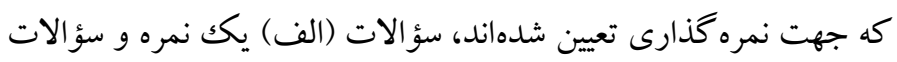

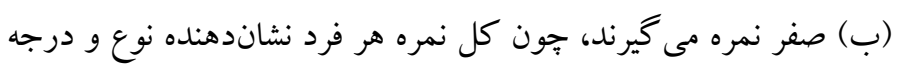

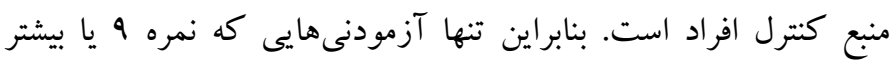
بخيرند، واجد منبع كنترل بيرونى و افرادى كه نمره كمتر بـيرند داراى منبع كنترل درونى خواهند بود. مجموع نمرات نشان دهنده منبع كنترل فرد بود. نمره بيشتر، بيانگر كرايش آزمودنى به سمت منبع كنترل بيرونى بود. اين

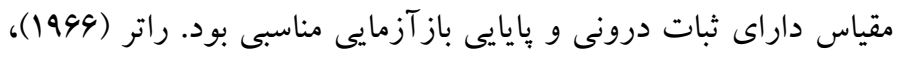

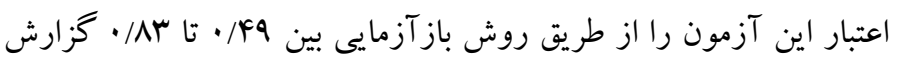
كرد. يايايى كودر - ريجاردسون كل خوشه نمرهها در حدود •V/ · بدست

2. Ruther's Control Source Control Questionnaire (RLCS)
1911 به يكك مقياس •ا گويهاى كاهش يافت (GSE-10) و به צr زبان

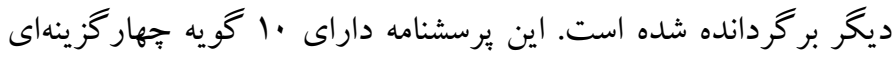

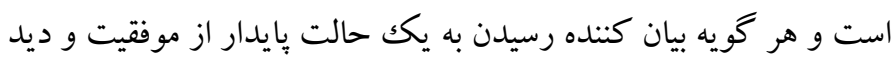

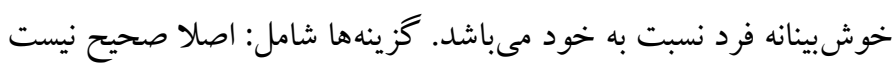

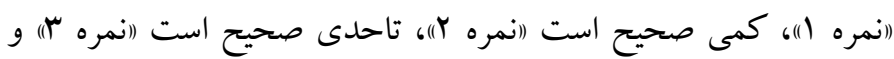

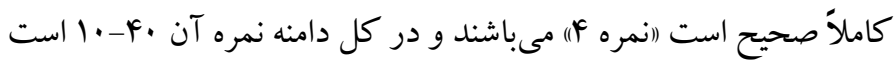
و نمره بالاتر نشان دهنده خودكار آمدى بالاتر افراد است. شوارزر و و هوه

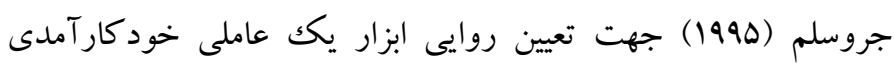

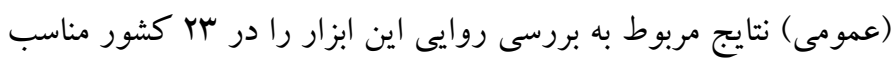

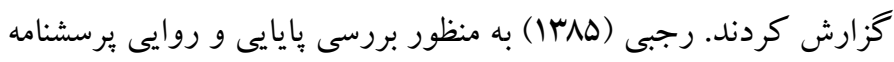
خود كار آمدى عمومى جهت كاربرد در موقعيتهاى بالينى، بزوهش هردهاى

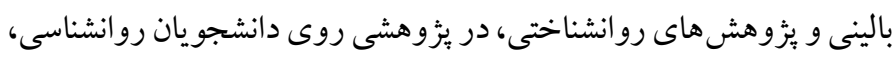

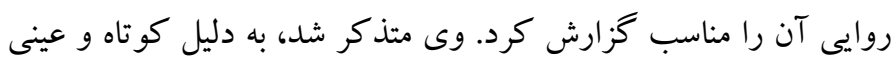

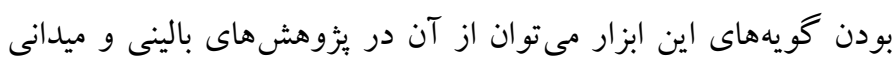

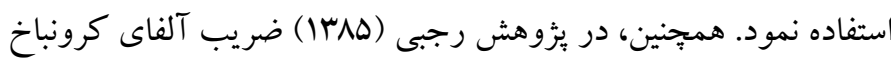

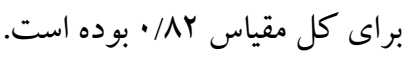

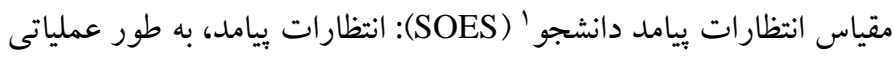
توسط مقياس انتظارات يِامد دانشجو تعريف شده است. گزينه هاى اين

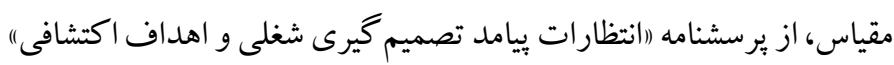
كه توسط هاكت، بهتز، كاسس و روجا - سينگك (1994) و به تز و وويتن

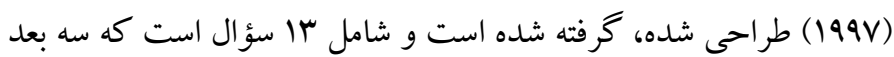

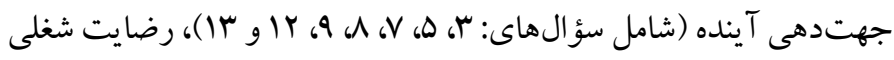

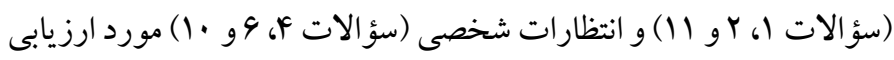

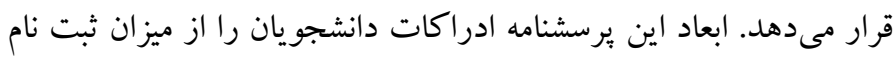

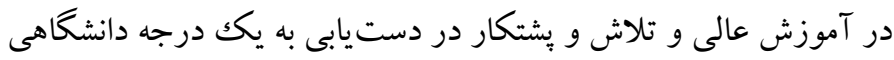

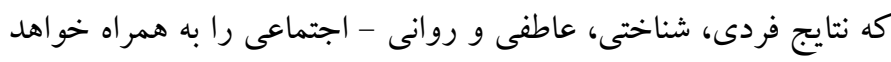

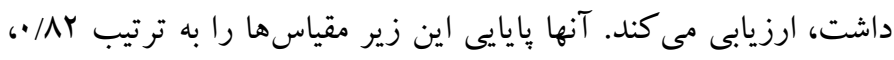

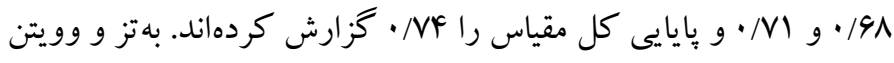

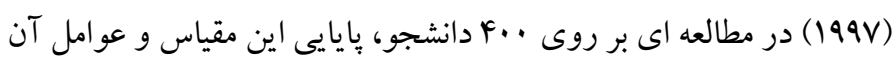

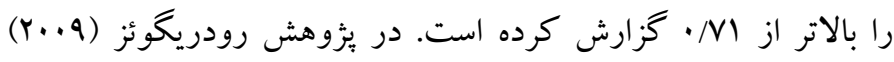

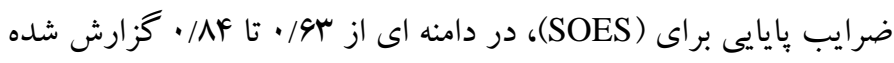

1. Student Outcome Expectations Scale (SOES) 
نتايج جدول r نشان مىدهد كه بعد از آموزش تغييرات سبكك زندگى در

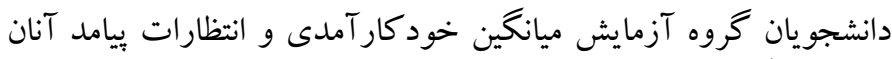

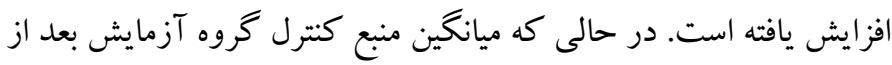

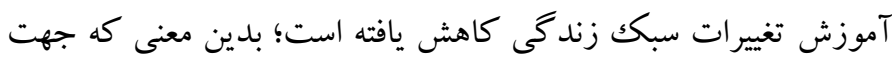

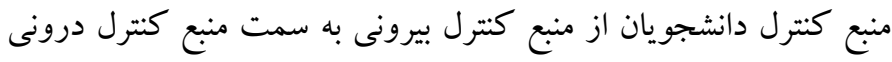

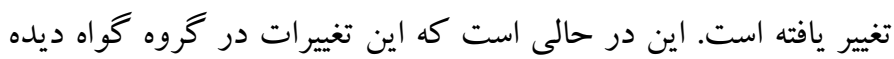

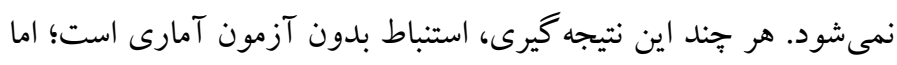

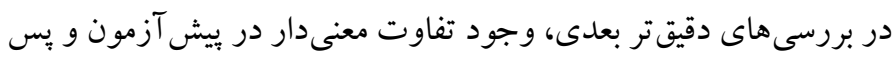

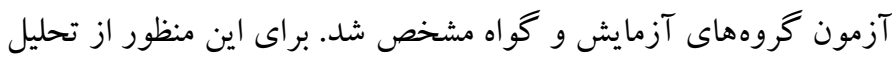

$$
\text { كواريانس استفاده شد (جدول r). }
$$

آمد. آلفاى كرونباخ براى اين مقياس VV/· گز ارش شده است. در يزوهش

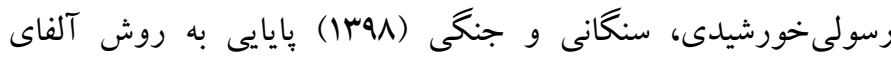

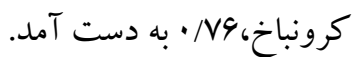

\section{يافتهها} در هر دو گروه آزمايش و گگواه درصد بيشترى از دانشجويان گروه نمونه

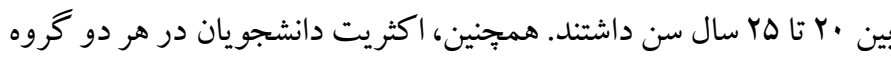
آزمايش و گواه دختر بودند و در مقطع كارشناسى و رشتهای حوزئ على علوم

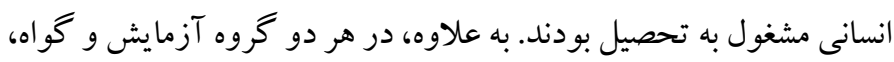
وضعيت اقتصادى خانو ادهٔ اكثريت دانشجويان در حد متوسط بود دون بنابر اين، مىتوان گفت كه گروههاى آزمايش و گواه با يكديخر از لحاظ ويز گى هاى جمعيتشناختى، همكنى تقريبى داشتند.

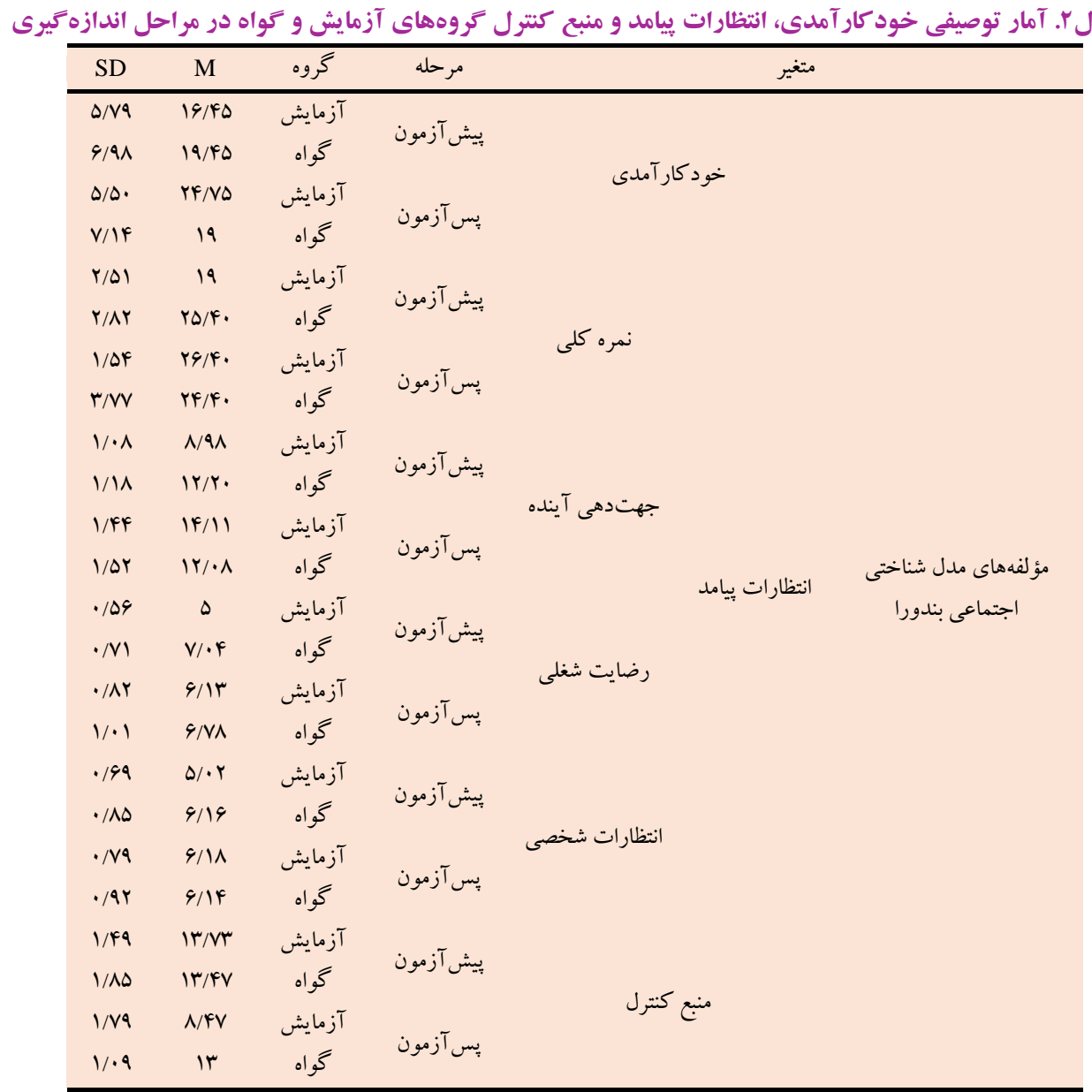




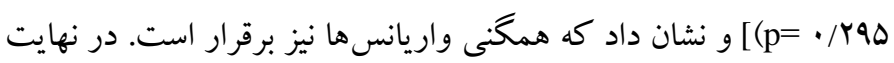

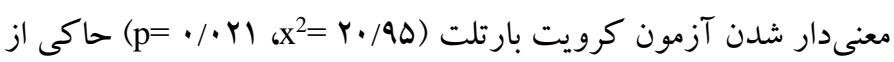
عدم وجود همخطى جِند كانه بين متغيرهاى همبر اش ها (ييش آزمونها

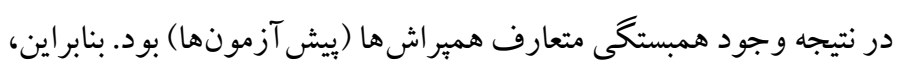

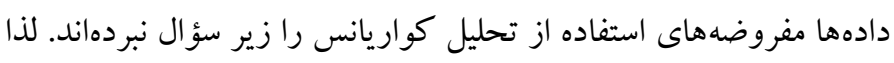
با توجه به رعايت مفروضهها، مى توان از آزمون تحليل كواريانس استفاده

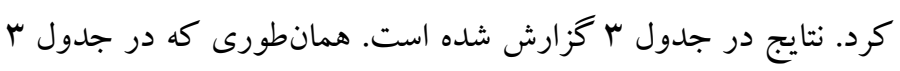
مشاهده مىشود يس از خارج كردن اثر بيش آزمون به روش ترد تحليل

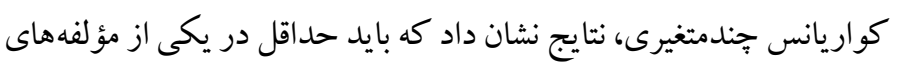

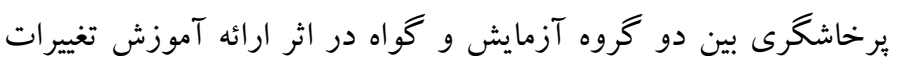

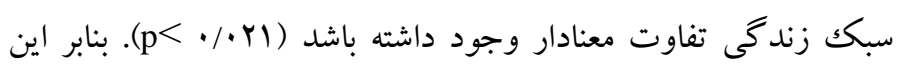
جهت بررسى اين نكته كه معنادارى مشاهده شده در كدام يكك از متغيرهاى بثوهش است، در جدول F به بررسى تحليل كوواريانس تك مت متغيرى يرداخته شد.

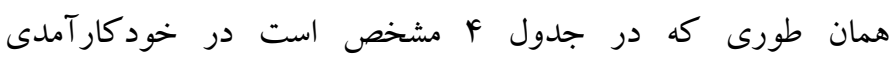

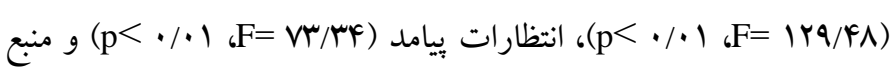

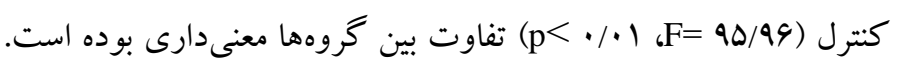

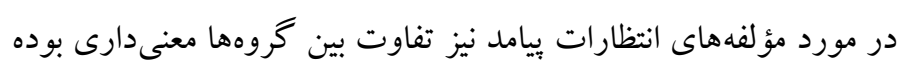

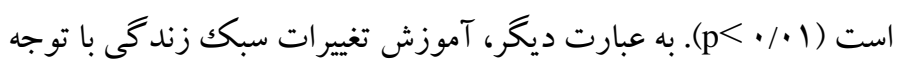

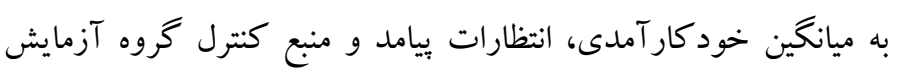

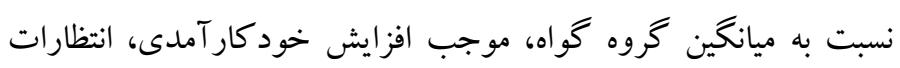
ييامد و منبع كنترل درونى در آزمودنىهاى گروه آزمايش شده است.
قبل از به كار گيرى تحليل كوواريانس، مفروضههاى آن بررسى گرديد.

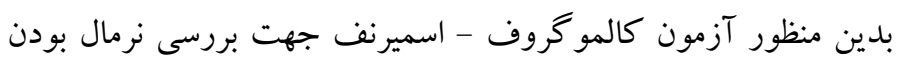
متغيرهاى يزوهش اجر ا شد و نتايج نشان داد توزيع نمرات خود كار آمدى درى

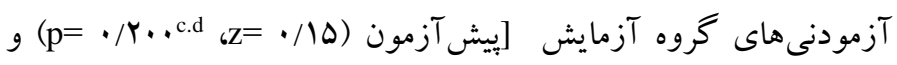

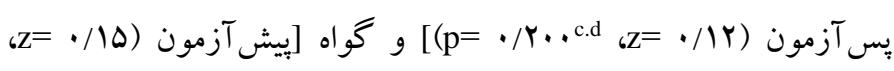

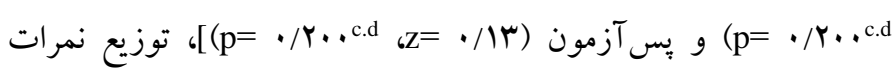

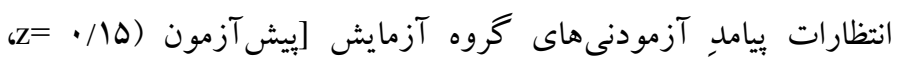
(p= • / / . . c.d

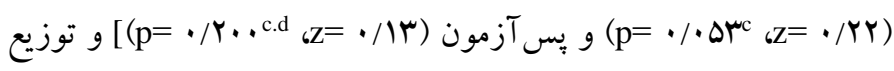

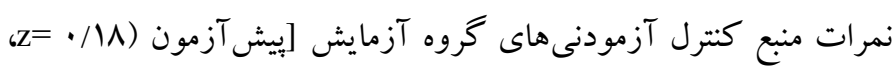

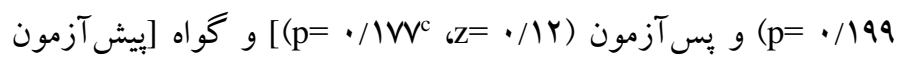

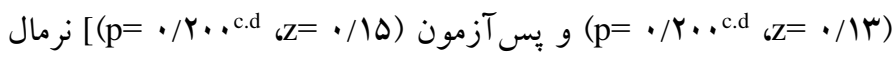
است. مفروضه ديخر مربوط به همكنى شيب رگرسيون بود كه از طريق

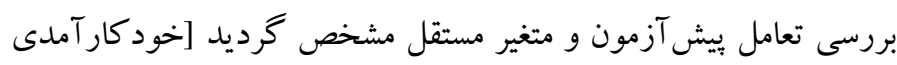

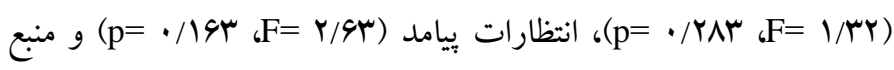

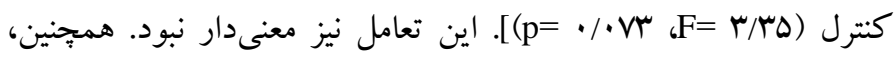
آزمون باكس جهت بررسى همخنى ماتريسهاى واريانس كوواريانس

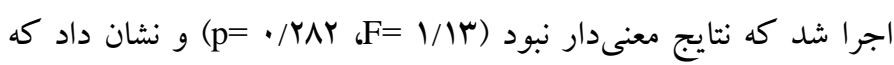
ماتريس هاى كوواريانس متغير وابسته براى سطوح مختلف متغير مستقل

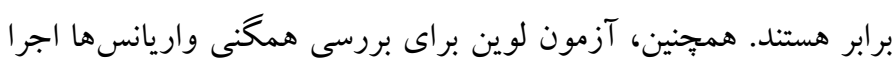

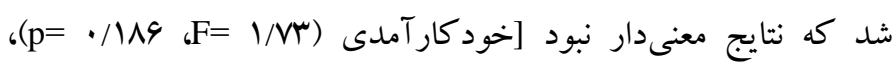

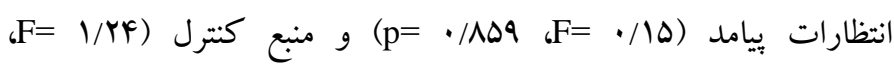

\begin{tabular}{|c|c|c|c|c|c|c|c|c|}
\hline توان آمارى & اندازه اثر & $\mathrm{p}$ & $\mathrm{F}$ & خطbا df & فرضيه & مقدار & نام آزمون & متغيرها \\
\hline 1 & $\cdot / A F$ & $\cdot / \cdot 1$ & YN/I. & r & $r$ & $\cdot / A F$ & آزمون اثر ييلايى & \multirow{8}{*}{ مُناختى اجتماعى مداى } \\
\hline 1 & - /AF &.$/ \cdot 1$ & $r N / 1$. & r & $r$ &.$/ 19$ & آزمون لامبداى ويلكز & \\
\hline 1 & $\cdot / A F$ &.$/ \cdot 1$ & $r N / 1$. & r & $r$ & $\Delta / r \Delta$ & آزمون اثر هتلينك & \\
\hline 1 & $\cdot / A F$ &.$/ \cdot 1$ & YN/I. & r & $r$ & $\Delta / r \Delta$ & آزمون بزر كترين ريشه روى & \\
\hline 1 & $\cdot 199$ &.$/ \cdot 1$ & $11 / 4 \pi$ & r & $r$ &.$/ 91$ & آزمون اثر ييلايى & \\
\hline 1 & .199 &.$/ \cdot 1$ & $11 / 4 \pi$ & r & $r$ & . & آزمون لامبداى ويلكز & \\
\hline 1 &.$/ 99$ &.$/ \cdot 1$ & $11 / 4 \pi$ & r & $r$ & $r / 1 \Lambda$ & آزمون اثر هتلينگك & \\
\hline 1 & .199 &.$/ \cdot 1$ & $11 / k \pi$ & r & $r$ & $r / M \Lambda$ & آزمون بزركترين ريشه روى & \\
\hline
\end{tabular}


جدولع. نتايج تحليل كواريانس روى ميانتين یس آزمون خود كار آمدى، انتظارات ييامد و منبع كنترل كروهها با كنترل ييش آزمون

\begin{tabular}{|c|c|c|c|c|c|c|c|c|}
\hline power & $\eta 2$ & F & MS & df & SS & & متغير & \\
\hline 1 & $\cdot|\Lambda|$ & $9 \mathrm{~N} / \mathrm{S}^{* * *}$ & $109 \Delta / V Y$ & 1 & $109 \Delta / V Y$ & ييش آزمون & \multirow{2}{*}{ خود كار آمدى } & \multirow{12}{*}{ شناختى اجتماعى لفهاى مدل } \\
\hline 1 & • & $\mid Y Q / F \Lambda^{* * *}$ & rGMN/v. & 1 & rGMN/V. & عضويت گروهى & & \\
\hline 1 & $\cdot / v$ & $99 / \Gamma^{* * *}$ & $Q 1 Y \cdot / 4 \wedge$ & 1 & $91 \% \cdot / 4 A$ & ييش آزمون & \multirow{2}{*}{ نمره كلى } & \\
\hline 1 & $\cdot / N$ & $V \Psi / Y f^{* * s}$ & $\mid V F V F / \Delta \Lambda$ & 1 & $\mid V F V F / \Delta \Lambda$ & عضويت گروهى & & \\
\hline 1 & $\cdot 194$ & $\mathrm{FV} / \mathrm{V} \cdot$ *** & $r \cdot \Delta / \Delta r$ & 1 & $r \cdot \Delta \Delta / \Delta r$ & ييش آزمون & \multirow{3}{*}{ جهتدهى آينده } & \\
\hline 1 & $\cdot / F^{F}$ & $V N / \Delta F^{* * *}$ & $r \cdot r r / 9 \Lambda$ & 1 & $r \cdot r r / 9 \Lambda$ & عضويت گروهى & & \\
\hline 1 & $\cdot / 4 \Lambda$ & $r r / W^{* * *}$ & $F \mid r / 90$ & 1 & $F \mid r / 90$ & يِيش آزمون & & \\
\hline 1 & .194 & $K G / K Y^{* * *}$ & $1 \cdot \Lambda \Delta / F \Delta$ & 1 & $1 \cdot \Lambda \Delta / F \Delta$ & عضويت گروهى & \multirow{3}{*}{ رضايت شغلى } & \\
\hline 1 & $\cdot / F V$ & $r \Delta / \cdot \Lambda^{* * * *}$ & $M F q / v D$ & 1 & $M F q / v \Delta$ & بيش آزمون & & \\
\hline 1 & .199 & $\Delta Q / / F^{* * * *}$ & $991 / \cdot 1$ & 1 & $991 / \cdot 1$ & عضويت گروهى & & \\
\hline 1 & $\cdot / \mathrm{NG}$ & VQ/qr** & $V \mid f / \cdot \Lambda$ & 1 & $V \mid F / \cdot 1$ & يِش آزمون & \multirow{2}{*}{ منبع كنترل } & \\
\hline 1 & $\cdot / \mathrm{V} 9$ & $৭ \Delta / ৭ 9^{* * *}$ & NDG/IFY & 1 & NDG/IFY & عضويت گروهى & & \\
\hline
\end{tabular}

مقابله مؤثر با مشكلات يارى رساند، اهميت ويثهاى دارد (تيلور و همكاران،

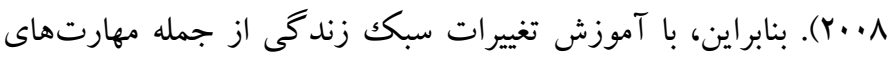

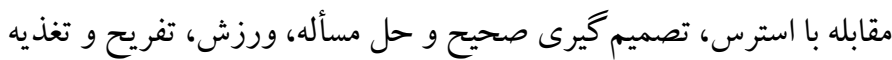

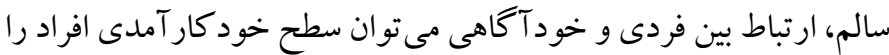

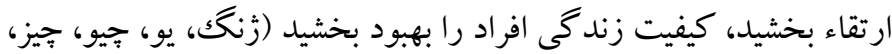

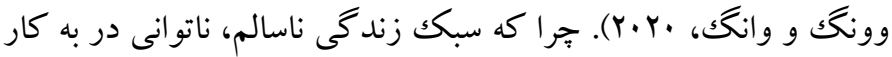
بردن تكنيككهاى ارتباطى مؤثر، عدم استفاده از راه كارهاى مقابلهاى مؤثر وابسته به موقعيت، منجر مى شود فرد دجار مشكلات عاطفى و ارتباطى شود

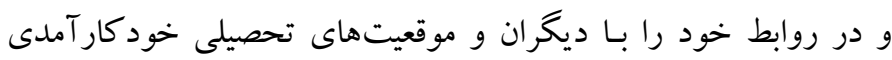
ضعيفى از خود نشان دهد. يكى از برنامههاى اين بثروهش در جهت افزايش

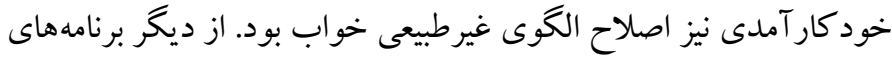

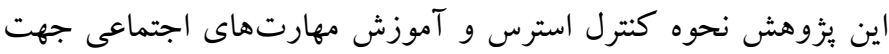

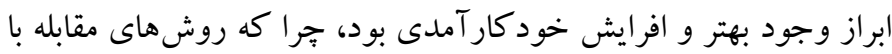

$$
\text { استرس ارتباط معنى دارى با خود كار آمدى دارند. }
$$

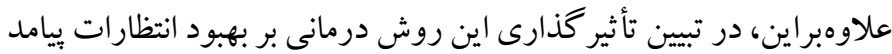

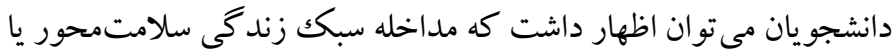

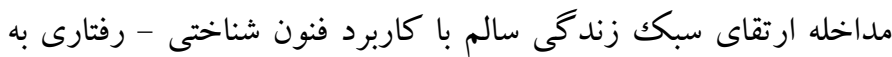

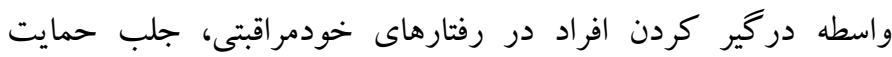
اجتماعى و بهبود علائم روانشناختى سبب ارتقاى اميدوارى و انتظارات ييامد مثبت مى گردند (بنسون، 19.Y). نكته ديكر اينكه آموزش سبك
بحث و نتيجه تيرى

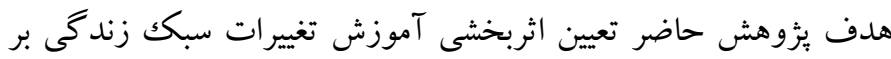

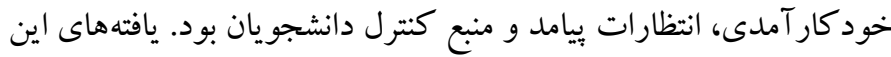

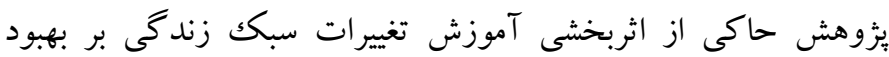

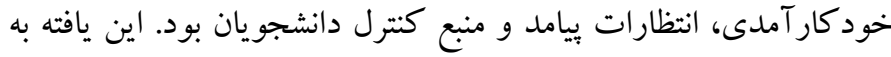

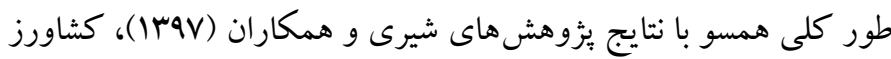

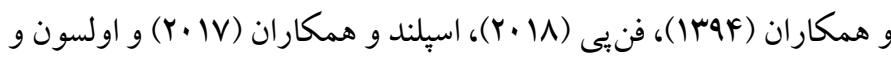

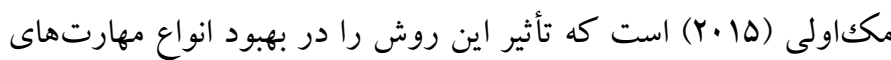
شناختى اجتماعى، نظير خودينداره تحصيلى، خود كارآمدى، انتظارات ييامد و منبع كنترل نشان دادهاند. در تبيين تأثير كذارى اين روش درمانى بر بهبود خود كار آمدى دانشجويان

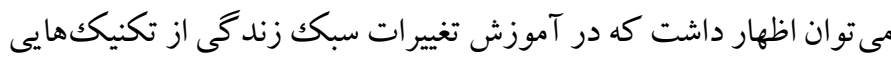
مختلفى به منظور ارتقاء مهارتهاى ارتباط مؤثر بين فردى كه از اصلى ترين مؤلفههاى خود كار آمدى در روابط بين فردى استفاده مى شود.

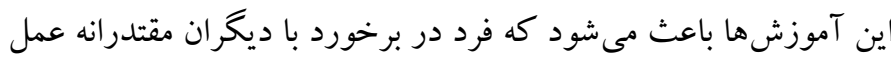

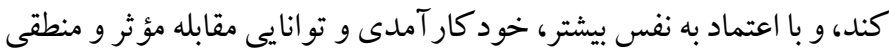

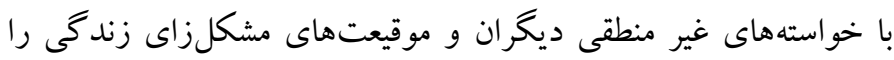

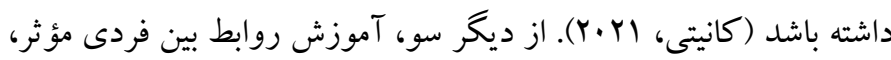
افراد را در جهت برقرارى روابط سالم و سازنده با افر ادى كه حمايتهاى عاطفى، اطلاعاتى و ابزارى آنها مىتواند به فرد در خودكار آمدى براى 
را كه در نتيجه آموزشهاى تغيير سبك زندگى اش به دست آمده است به

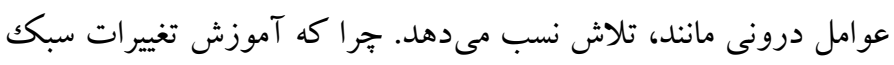

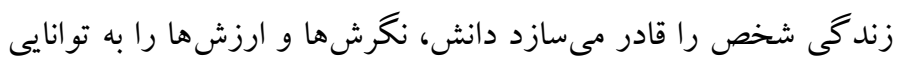

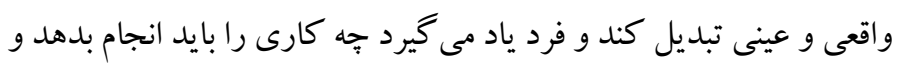

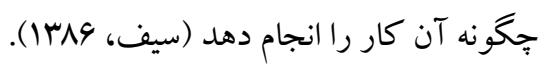
يافته ها يزوهش حاضر، فقط قابل به تعميم به دانشجويانى است كه ملاكك

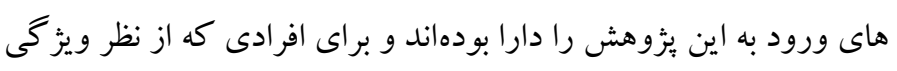

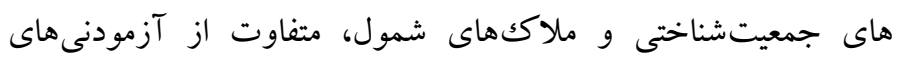

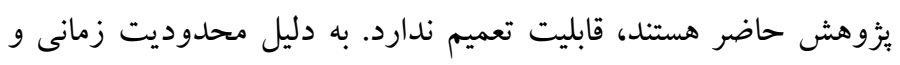

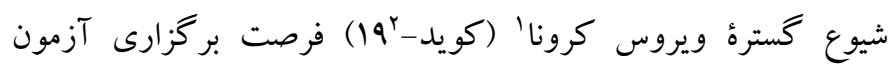

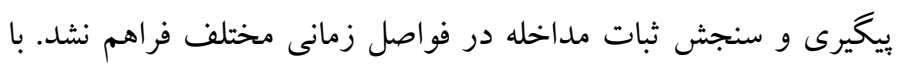

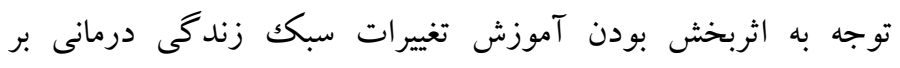

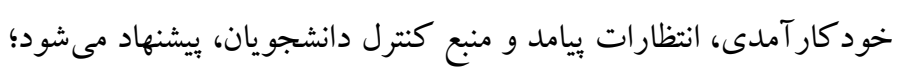

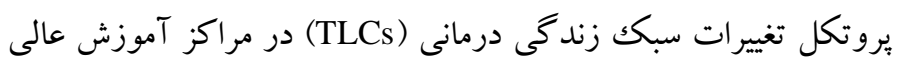
شهرهاى مختلف استفاده شود و اثربخشى آن با ساير روشهاى درمائ درمانى مقايسه شود.

ملاحضات اخلاقى إخى يبيروى از اصول اخلاق ئزوهش: اين مقاله بر كرفته از رساله دكترى نويسنده نخست

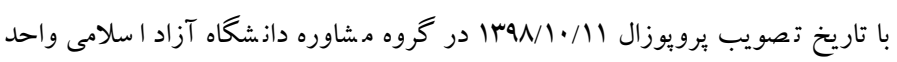
علوم و تحقيقات تهران اسـت. در اين يُزوهش ملاحظات اخلاقى ماند رضـايت كامل

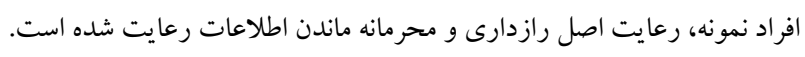
حامى مالى: اين مطالعه بدون حامى مالى و در قالب رساله دكترى انجام شده است.

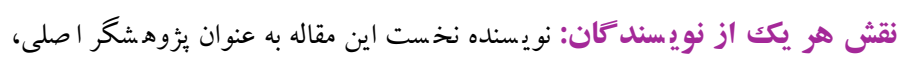

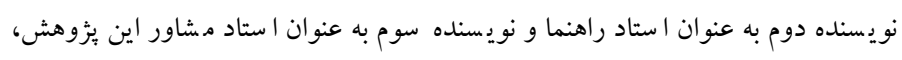

نقش داشتند.

تضاد منافع: اين يزوهش براى نويسند كان هيج كونه تضاد منافعى نداشته است.

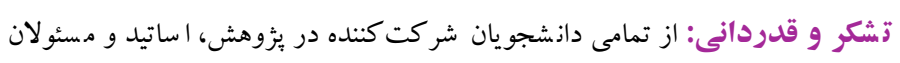

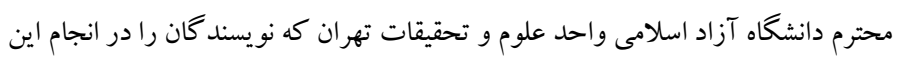
يثوهش يارى و همر اهى كردهاند، تشكر و قدردانى مى شيود.
زندگى سلامت محور ميزان دانش و آكاهى هاى افراد را افزايش مىدهد و باعث تغيير نخرش ها، عادات، رفتارهاى نادرست فرد و در نتيجه انتظارات

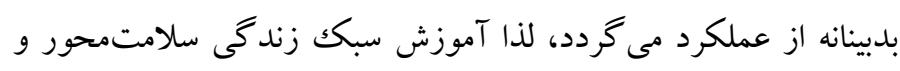
رفتارهاى ارتقاءدهنده سلامت مىتواند فرد را بر آن دارد كه زمينههاى

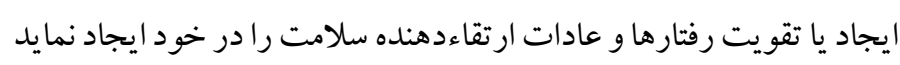

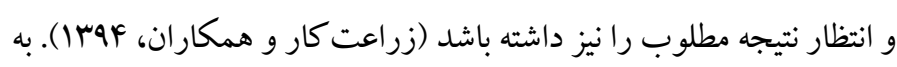

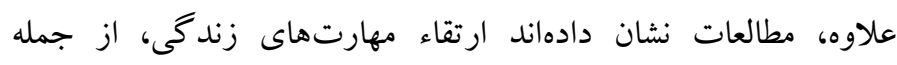
مهارت هاى مقابلهاى و توانايىهاى روانى - اجتماعى فرد را براى مقاب مهابله

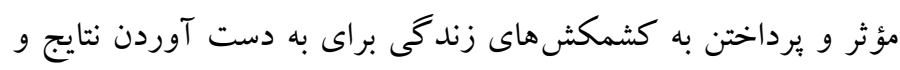

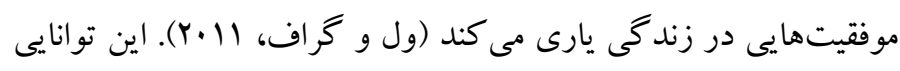

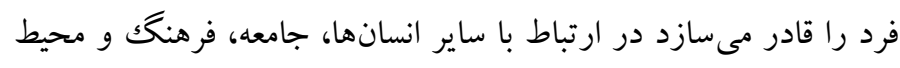
خود مثبت و سازشيافته عمل كند و از اقدامات خود، انتظار نتايج متناسب داشته باشد (كلينيكه، 1991).

در نهايت، در تبين جُخونى تأثير گذارى آموزش تغييرات سبك زند در تغيير جهت منبع كنترل بيرونى دانشجويان به درونى مى توان اظهار داشت نهاتي

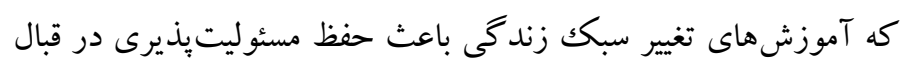

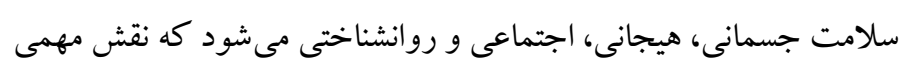

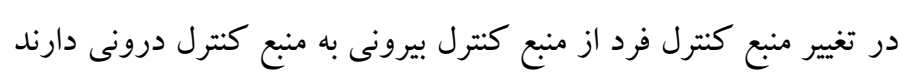

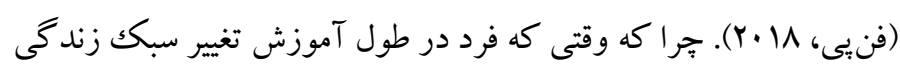

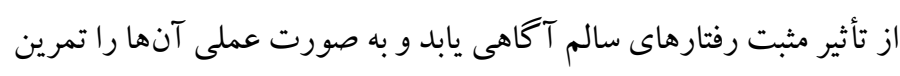

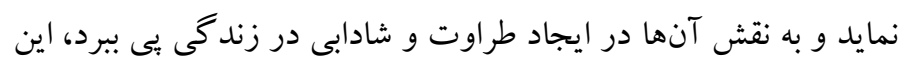

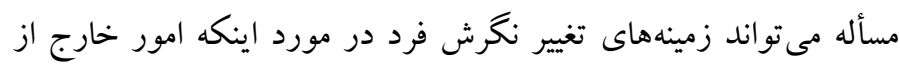
كنترل فرد هستند و او هيج نقشى در تغيير سبك زند زئى خونى خود و نتايج

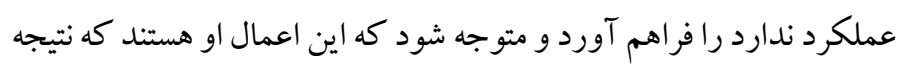

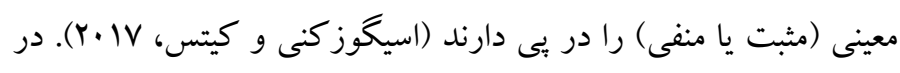

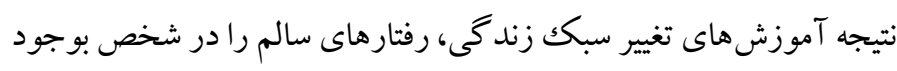

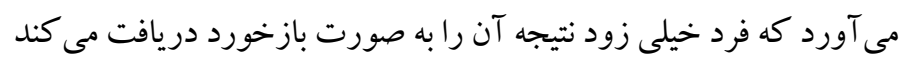

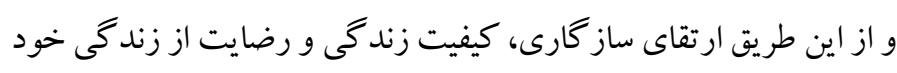

2. Covid-19

${ }^{1}$. coronavirus 


\section{References}

Abasi, M., Davoodi, H., Heidari, H., \& Pirani, Z. (2020). Comparing the effectiveness of teaching cognitivemetacognitive strategies and teaching positive psychology on academic self-efficacy, academic burnout and learning strategies. Journal of School Psychology, 9(4), 144-166. [link]

Açıkgöz Çepni, S., \& Kitiş, Y. (2017). Relationship between healthy lifestyle behaviors and health locus of control and health-specific self-efficacy in university students. Japan Journal of Nursing Science, 14(3), 231-239. [link]

Allen, T. W. (1972). The individual psychology of Alfred Adler: An item of history and a promise of a revolution. The Counseling Psychologist, 3(1), 324. [link]

Arakeri, S., \& Sunagar, B. (2017). Locus of control: influence of internality, externality-others, externality-chance among management students. The International Journal of Indian Psychology, 4(2), 155-162. [link]

Benson, M. (2016). Lifestyle migration: Expectations, aspirations and experiences. Routledge. [link]

Betz, N. E., \& Voyten, K. K. (1997). Efficacy and outcome expectations influence career exploration and decidedness. The Career Development Quarterly, 46(2), 179-189. [link]

Bhat, A. A., DeWalt, D. A., Zimmer, C. R., Fried, B. J., \& Callahan, L. F. (2010). The role of helplessness, outcome expectation for exercise and literacy in predicting disability and symptoms in older adults with arthritis. Patient education and counseling, 81(1), 73-78. [link]

Bonitz, V. S., Larson, L. M., \& Armstrong, P. I. (2010). Interests, self-efficacy, and choice goals: An experimental manipulation. Journal of Vocational Behavior, 76(2), 223-233. [link]

Cannity, K. M., Banerjee, S. C., Hichenberg, S., LeonNastasi, A. D., Howell, F., Coyle, N., ... \& Parker, P. A. (2021). Acceptability and efficacy of a communication skills training for nursing students: building empathy and discussing complex situations. Nurse Education in Practice, 50, 102928. [link]

Corey, G. (2017). Theory and practice of counseling and psychotherapy. Nelson Education. [link]

Diaz, M. E. (2019). Exploring Latino Preservice Teachers' Attitudes and Beliefs about Learning and Teaching Science: What Are the Critical Factors?.
International Journal of Research in Education and Science, 5(2), 574-586. [link]

Dixon, H., Hawe, E., \& Hamilton, R. (2020). The case for using exemplars to develop academic self-efficacy. Assessment \& Evaluation in Higher Education, 45(3), 460-471. [link]

Donoghoe, M. C., Dolan, K. A., \& STIMSON, G. V. (1992). Life-style factors and social circumstances of syringe sharing in injecting drug users. British Journal of Addiction, 87(7), 993-1003. [link]

Espeland, M. A., Luchsinger, J. A., Baker, L. D., Neiberg, R., Kahn, S. E., Arnold, S. E., ... \& Hazuda, H. P. (2017). Effect of a long-term intensive lifestyle intervention on prevalence of cognitive impairment. Neurology, 88(21), 2026-2035. [link]

Estaji, Z., Akbarzadeh, R., Tadayyonfar, M., Rahnama, F., Zardouz, H., \& Najar, L. (2006). Study of the life style of people in Sabzevar, Iran. Journal of Sabzevar University of Medical Sciences, 13(3), 134-139. [link]

Farnoodian, P. (2016). The effectiveness of group reality therapy on mental health and self-esteem of students. Int J Med Res Health Sci (IJMRHS), 5(9), 18-24. [link]

Feldman, D. B., \& Kubota, M. (2015). Hope, self-efficacy, optimism, and academic achievement: Distinguishing constructs and levels of specificity in predicting college grade-point average. Learning and Individual Differences, 37, 210-216. [link]

Galobardes, B., Costanza, M. C., Bernstein, M. S., Delhumeau, C., \& Morabia, A. (2003). Trends in risk factors for lifestyle-related diseases by socioeconomic position in Geneva, Switzerland, 1993-2000: health inequalities persist. American journal of public health, 93(8), 1302-1309. [link]

Hackett, G., Betz, N. E., Casas, J. M., \& Rocha-Singh, I. A. (1992). Gender, ethnicity, and social cognitive factors predicting the academic achievement of students in engineering. Journal of counseling Psychology, 39(4), 527. [link]

Hamidi, F., \& Jalilian, H. (2019). Effects of MindfulnessBased Cognitive Therapy on Attributional Styles of Students. Quarterly Journal of Family and Research, 15(4), 85-102. [link]

Hamidi, F., Jalilian H. (2019). Effects of MindfulnessBased Cognitive Therapy on Attributional Styles of Students. Quarterly Journal of Family and Research, 15(4), 85-102. [link]

Hubley, J., \& Leeds, F. (2002). Health Empowerment, Health Literacy and Health Promotion Putting It All Together. Leeds International Health Promotion 
(online), February. Fuente: http://www.hubley.co.uk/lhlthempow.htm (last accessed 31 January 2007). [link]

Keshavarz, G., Nazari, A., Zahrakar, K., Sarami, G. (2015). Group Lifestyle Therapy Based on Individual Psychology and its impact on Students' Procrastination and Academic Achievement. Quarterly Journal of Family and Research, 12(1), 107-124. [link]

Khadavi, A., \& Vakili, A. (2011). Relationship between achievement motivation, source of control, selfconcept and academic achievement in first-grade high school students in tabriz. J Educ Sci, 4, 45-66. [link]

Kleinke, C. L. (1998). Coping with life challenges. Pacific Grove, Calif.: Brooks/Cole. [link]

Landry, C. C. (2003). Self-efficacy, motivation, and outcome expectation: Correlates of college students' intention certainty (Doctoral dissertation). Louisiana State University, Baton Rouge, LA. [link]

O'Sullivan, G. (2011). The relationship between hope, eustress, self-efficacy, and life satisfaction among undergraduates. Social indicators research, 101(1), 155-172. [link]

Olson, E. A., \& McAuley, E. (2015). Impact of a brief intervention on self-regulation, self-efficacy and physical activity in older adults with type 2 diabetes. Journal of behavioral medicine, 38(6), 886-898. [link]

Rajabi, G. R. (2006). Reliability and validity of the general self-efficacy beliefs scale (gse-10) comparing the psychology students of shahid chamrin university and azad university of marvdasht. Quarterly Journal of New Thoughts on Education, 2(1), 111122. [link]

Rasouli, F., \& Sangani, A. (2019). The relationship between academic procrastination, locus of control and achievement motivation with academic achievement in nursing student. Journal of Nursing Education, 8(1), 21-28. [link]

Rodriguez, C. M. (2009). The impact of academic selfconcept, expectations and the choice of learning strategy on academic achievement: the case of business students. Higher Education Research \& Development, 28(5), 523-539. [link]

Rotter, J. B. (1966). Generalized expectancies for internal versus external control of reinforcement. Psychological monographs: General and applied, 80(1), 1. [link]
Saif, A. A. (2007). Educational psychology: psychology of learning and Instruction. Tahran: Agah Publication. [link]

Sawai, R. P. (2018). Relationship between religiosity, locus of control and academic achievement among IIUM students. Research Gate, (June), 1-61. [link]

Scherer, R. (2013). Further evidence on the structural relationship between academic self-concept and self-efficacy: On the effects of domain specificity. Learning and Individual Differences, 28, 9-19. [link]

Schultz, D. P., \& Schultz, S. E. (2016). Theories of personality. Cengage Learning. [link]

Schunk, D. H., \& DiBenedetto, M. K. (2020). Motivation and social cognitive theory. Contemporary Educational Psychology, 60, 101832. [link]

Schwarzer, R., \& Jerusalem, M. (1995). Generalized selfefficacy scale. In S. Wright, M. Johnston, \& J. Weinman, (Eds.), Measures in Health Psychology: A User's Portfolio. Causal and Control Beliefs (pp. 35-37). Windsor, UK: nferNelson. [link]

Shafi Naderi, M., Kodivar, P., Arab Zadeh, M., \& Sorami, G. (2013). An analysis of the factor structure reliability and validity of students outcome expectancy scale. Educational Measurement, 10(3), 21-35. [link]

Shiri, M. J., Ardakani, Z. A., \& Mirsaleh, Y. R. (2018). The Effectiveness of Lifestyle Change-Based Interventions with Emphasis on Educational Lifestyle on Educational Self-Concept of Veterans' Children. Journal of Military Medicine, 20(5), 546553. [link]

Taylor, J. L., Smith, P. J., Babyak, M. A., Barbour, K. A., Hoffman, B. M., Sebring, D. L., ... \& Csik, I. (2008). Coping and quality of life in patients awaiting lung transplantation. Journal of Psychosomatic Research, 65(1), 71-79. [link]

Thomas, S. P. (2012). Therapeutic Lifestyle Changes (TLCs) and Mental Health. Issues in mental health nursing, 33(4), 199-199. [link]

Toussi, M. T. M., \& Ghanizadeh, A. (2012). A Study of EFL Teachers' Locus of Control and Self-regulation and the Moderating Role of Selfefficacy. Theory \& Practice in Language Studies, 2(11). [link]

Van Pay, K. (2018). Intent to engage in therapeutic lifestyle changes: Impact of an intervention, selfefficacy expectations, outcome expectations, and locus of control. Graduate Theses and Dissertations. 16683. [link]

Walsh, R. (2011). Lifestyle and mental health. American Psychologist, 66(7), 579. [link] 
Welle, P. D., \& Graf, H. M. (2011). Effective lifestyle habits and coping strategies for stress tolerance among college students. American Journal of Health Education, 42(2), 96-105. [link]

Williams, D. M. (2010). Outcome expectancy and selfefficacy: Theoretical implications of an unresolved contradiction. Personality and Social Psychology Review, 14(4), 417-425. [link]

Zeraatkar, M., Rahimian Boogar, I., Talepasand, S., \& Amin, A. (2016). The effectiveness of healthy lifestyle promotion intervention on quality of life in patients with congestive heart failure via cognitivebehavioral procedure. Journal of Shahid Sadoughi University of Medical Sciences, 23(11), 1094-1107. [link]

Zheng, X., Yu, H., Qiu, X., Chair, S. Y., Wong, E. M. L., \& Wang, Q. (2020). The effects of a nurse-led lifestyle intervention program on cardiovascular risk, self-efficacy and health promoting behaviours among patients with metabolic syndrome: randomized controlled trial. International Journal of Nursing Studies, 109, 103638. [link] 